US Army Corps

of Engineers $s_{\circledast}$

Engineer Research and

Development Center

Dredging Operations and Environmental Research Program

Use of an Acoustic Camera to Evaluate the Performance of Tickler Chains and Draghead Deflectors for Sea Turtle Protection during Hopper Dredging in the United States of America

Dena Dickerson, Timothy Welp, Stephen Willis,

May 2018

and Douglas Novy

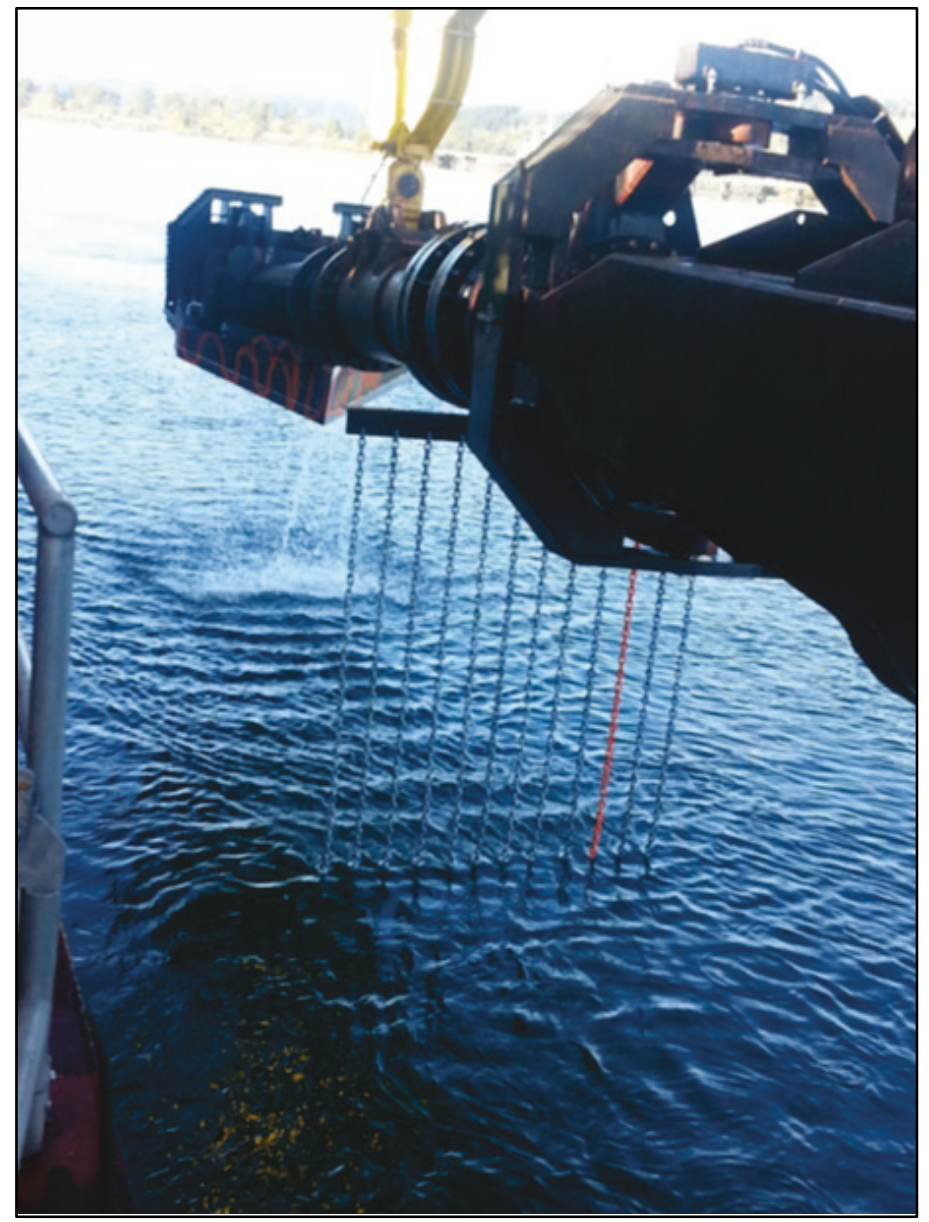


The U.S. Army Engineer Research and Development Center (ERDC) solves the nation's toughest engineering and environmental challenges. ERDC develops innovative solutions in civil and military engineering, geospatial sciences, water resources, and environmental sciences for the Army, the Department of Defense, civilian agencies, and our nation's public good. Find out more at www.erdc.usace.army.mil.

To search for other technical reports published by ERDC, visit the ERDC online library at http://acwc.sdp.sirsi.net/client/default. 


\section{Use of an Acoustic Camera to Evaluate the Performance of Tickler Chains and Draghead Deflectors for Sea Turtle Protection during Hopper Dredging in the United States of America}

Dena Dickerson

Environmental Laboratory

U.S. Army Engineer Research and Development Center 3909 Halls Ferry Road

Vicksburg, MS 39180-6199

Timothy Welp

Coastal and Hydraulics Laboratory

U.S. Army Engineer Research and Development Center

3909 Halls Ferry Road

Vicksburg, MS 39180-6199

Stephen Willis

U.S. Army Engineer District, San Francisco

1455 Market St \#16

San Francisco, CA 94103

Douglas Novy

Great Lakes Dredge and Dock

2122 York Road

Oak Brook, IL 60523

Final report

Approved for public release; distribution is unlimited.

Prepared for U.S. Army Corps of Engineers

Washington, DC 20314-1000

Under Project No. 468436, “Dredging Operations and Environmental Research Program" 


\section{Abstract}

Potential risk for incidental take of sea turtles exists during hopper dredging throughout sea turtle coastal habitats. While the international dredging community has incorporated turtle protection methods developed by the U.S. Army Corps of Engineers, alternative protection measures have also been tried. One such method is a curtain of chains hanging off the dragarm pipe ahead of the draghead, which is intended to disturb a turtle on or near the seafloor and avoid a turtle take by the draghead. Although these turtle tickler chains (TTC) have been used overseas, neither operational performance nor effectiveness in protecting sea turtles has been documented.

This study was the first step in evaluating TTC as a potential replacement for draghead turtle deflectors. The primary objective was to evaluate and document operational performance of this technology, not effectiveness of reducing incidental take. TTC operational performance was monitored using underwater camera systems over a short period of time whereas effectiveness for reducing incidental take of sea turtles would require analysis of endangered species observer monitoring data collected over a longer period. This study successfully demonstrated operational feasibility of deploying TTC off the dragarm and feasibility for mounting acoustic cameras on the dragarm for underwater monitoring.

DISCLAIMER: The contents of this report are not to be used for advertising, publication, or promotional purposes. Citation of trade names does not constitute an official endorsement or approval of the use of such commercial products. All product names and trademarks cited are the property of their respective owners. The findings of this report are not to be construed as an official Department of the Army position unless so designated by other authorized documents. 


\section{Contents}

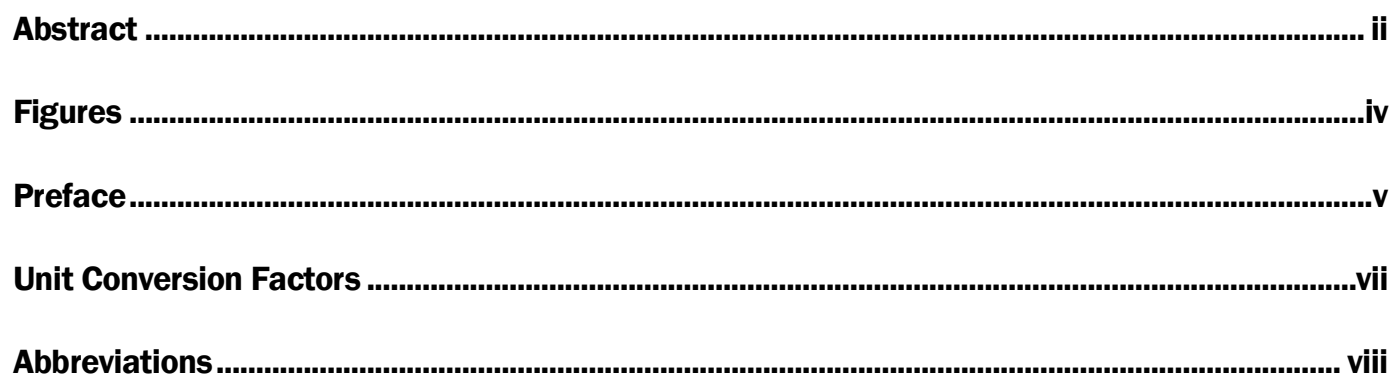

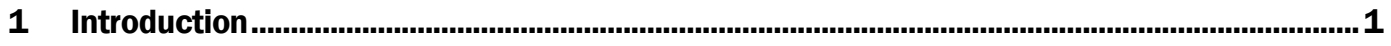

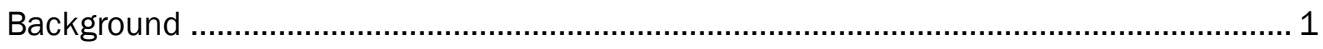

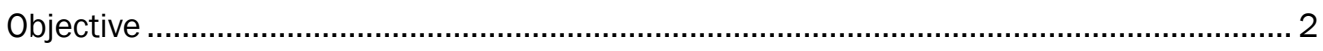

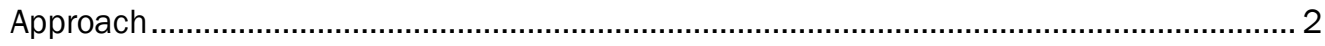

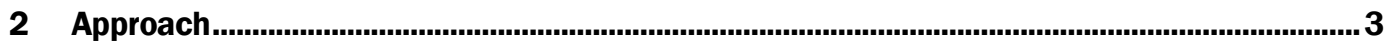

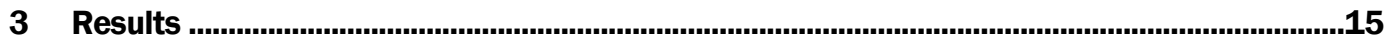

Preliminary test in San Francisco Bay, California ............................................................ 15

Testing at Kalaeloa Barbers Point, Oahu, HI................................................................. 17

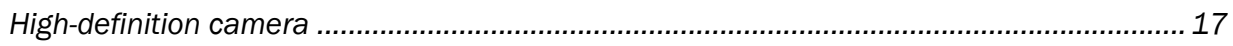

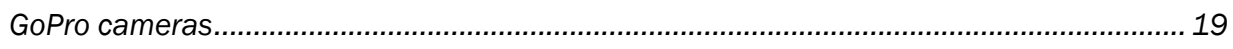

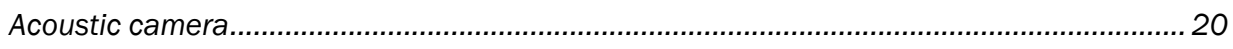

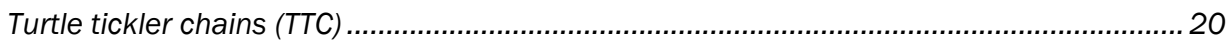

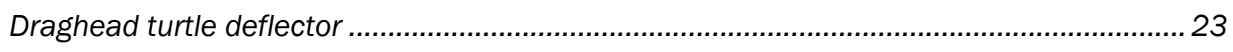

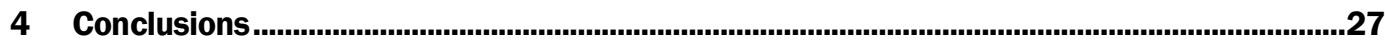

References ...............................................................................................................................29

Report Documentation Page 


\section{Figures}

Figure 1. Rigid design draghead turtle deflector and TTC on the Essayons port dragarm (looking aft)

Figure 2. GoPro camera in underwater housing and 700-lumen light source mounted on outboard gimbal frame of the dragarm

Figure 3. GoPro camera (red arrow) mounted on the dragarm above the chain array. ...................... 8

Figure 4. High-definition video camera lens with light and acoustic camera mount...........................9

Figure 5. Underwater video and acoustic camera systems viewing and recording station in

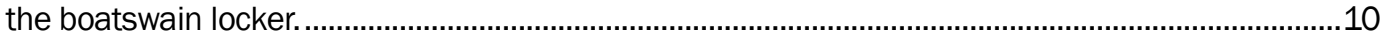

Figure 6. Damage to portside chain bracket and acoustic camera mount. ......................................11

Figure 7. Revised camera and light mount configuration (aft looking forward) for Barbers Point $\mathrm{HI}$

Figure 8. Profile view of revised positions for the three camera systems relative to $T \mathrm{TC}$ and draghead (Kalaeloa Barbers Point, $\mathrm{HI}$ ).

Figure 9. Acoustic camera image of TTC free-streaming in water column over sand waves.............16

Figure 10. Acoustic camera image of tickler chains dragging over sand bottom. .............................16

Figure 11. Acoustic camera image of the draghead interacting with sand wave crest......................17

Figure 12. Image of video collected by the high-definition camera system showing chains dragging along the harbor sea bottom........................................................................................

Figure 13. The Essayons draghead and lower dragpipe covered in sediment.

Figure 14. Image of the chain array from the GoPro camera on the bottom of the dragarm turning gland

Figure 15. Acoustic camera image of chains free-streaming in water column above the harbor bottom.

Figure 16. Acoustic camera image of chains dragging on harbor bottom.

Figure 17. Photograph (left) of the bound chain array out of the water compared to the acoustic camera image (right) of chains free-streaming in the water column.

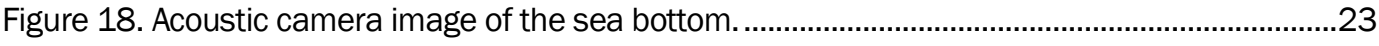

Figure 19. Acoustic camera image of the draghead with turtle deflector in water column.

Figure 20. Acoustic camera image of the draghead in mud with a sediment wave building up on turtle deflector.

Figure 21. Endangered species observer inspecting condition of TTC after dredging a load on the Essayons. 


\section{Preface}

This effort was supported by the U.S. Army Corps of Engineers (USACE) Dredging Operations and Environmental Research (DOER) Program (http://el.erdc.usace.army.mil/dots/doer/doer.html). The DOER Program is managed at the U.S. Army Engineer Research and Development Center (ERDC) by Dr. Todd Bridges, Environmental Laboratory (EL).

DOER is administered at the Coastal and Hydraulics Laboratory (CHL) under the USACE Navigation Research, Development, and Technology Transfer (RD\&T) Program. At the time this effort was conducted, Mr. Jeffery McKee was the Headquarters, USACE, (HQUSACE) Navigation Business Line Manager overseeing the DOER Program. Mr. W. Jeff Lillycrop, CHL, was the ERDC Technical Director for Civil Works and Navigation RD\&T. Mr. Charles E. Wiggins, CHL, was the ERDC Associate Technical Director for Navigation.

This study would not have been possible without the support of USACE Portland District including dredge Essayons support team members Mr. Jerry Gompers, Mr. Casey O’Donnell, Mr. Joe Bateman, Mr. Tim Berge, Mr. Mike Ott, and Ms. Liz Smock. The crew of the dredge Essayons, including Master James Holcroft, Master Larry Calame, Mr. Troy Ertzberger, Mr. Sam Repman, Mr. Bob Hudson, Mr. Ed Morgan, Mr. Nathan Webb, and Mr. Steve VanHorn, were instrumental in the study's success by their extra effort and late-night welding. Critical support was also provided by Mr. Jon Hosaka, Mr. Tom Smith, Ms. Jennifer Eugenio, and Ms. Nani Shimabuku with USACE Honolulu District; Mr. Michael Noah and Mr. Christopher Floyd with USACE Pacific Ocean Division; Ms. Cynthia Jo Fowler, Mr. William Brostoff, Ms. Jessica Burton-Evans with USACE San Francisco District; Mr. Phillip Bates with USACE Jacksonville District; Mr. Joel Moribe, Mr. Pat Opay, and Ms. Ann Garrett with National Oceanic and Atmospheric Administration-National Marine Fisheries Service-Pacific Island Region; Mr. Kevin Kelly, Ms. Ann Aoidis, Ms. Cyndi Vallejo, Mr. Ryan Wooster with Tetra Tech EM Inc.; Mr. Joe Burch and Ms. Jeanne Dorsey with Sound Metrics; Mr. Sean Mayfield with Outland Technology; Mr. Robert Ramsdell with Great Lakes Dredge and Dock Company; and Mr. John Henriksen and Mr. Mike Warwick with Manson Construction Company. 
The Director of ERDC-EL during the study was Dr. Beth Fleming, and the Director of ERDC-CHL was Mr. José E. Sánchez. The Commander of ERDC was COL Bryan S. Green, and the Director of ERDC was Dr. Jeffery Holland.

At the time of publication of this report, COL Bryan S. Green was Commander of ERDC, and Dr. David W. Pittman was the Director. 


\section{Unit Conversion Factors}

The conversions between non-SI units of measurement and SI (metric) units in this report are as follows:

\begin{tabular}{|l|c|l|}
\hline Multiply & By & To Obtain \\
\hline feet & 0.3048 & meters \\
\hline inches & 2.540 & centimeters \\
\hline inches & 25.40 & millimeters \\
\hline
\end{tabular}




\section{Abbreviations}

DOER Dredging Operations and Environmental Research Program

ERDC U.S. Army Engineer Research and Development Center

NMFS-PIR National Marine Fisheries Service - Pacific Island Region

POH USACE Honolulu District

TTC turtle tickler chains

USACE U.S. Army Corps of Engineers 


\section{Introduction}

\section{Background}

Of the seven species of sea turtles in the world, six are present throughout the coastal waters of the United States. Sea turtles are known to inhabit most temperate marine coastlines of the world and are listed as either threatened or endangered. Incidental entrainment or takes of sea turtles during hopper dredging operations have been documented since the U.S. Army Corps of Engineers (USACE) implemented sea turtle monitoring during dredging in Canaveral Harbor, FL, in 1980 (Dickerson et al. 2004). Endangered species monitoring has now been established throughout hopper dredging projects along the U.S. Atlantic and Gulf of Mexico coastlines. Additionally, during the past 37 years, numerous engineering and operational methods have been developed, tested, and implemented to protect sea turtles during hopper dredging projects along the Atlantic and Gulf of Mexico coastlines. Engineering methods involve a physical construction or modification of the dredge equipment to cause the desired change in conditions as opposed to operational methods that involve modification in the way that the dredge is operated to reduce risk. These protective measures have resulted in dramatic reductions in the rate of incidental take of sea turtles; however, efforts continue to develop additional protective methods to minimize risk to sea turtles while maintaining optimal dredging production and efficiency.

Potential risk for incidental take of sea turtles still exists during hopper dredging throughout sea turtle coastal habitats. Over the past 15 years, the international dredging community has also incorporated sea turtle protection methods developed by the USACE into some of their hopper dredging projects when possible. Social, economic, and environmental differences for international projects may prevent the use of some sea turtle protection methods typically used during U.S. dredging projects. Therefore, alternative protection measures have been tried during these international projects.

One such method is a curtain of chains hanging off the dragarm pipe ahead of the draghead, which is intended to disturb a turtle on or near the seafloor and avoid a turtle take by the draghead. These chains are designed to be dragged along the seafloor to startle or motivate a turtle on or near 
the seafloor to move away from the oncoming draghead. This equipment is referred to as tickler chains and is likewise named and similarly used by the fishing industry to motivate organisms to move off the seafloor ahead of fishing nets. Various versions of these turtle tickler chains (TTC) have been deployed during hopper projects outside the U.S. including Gorgon, Western Australia and São João da Barra, Brazil. Although TTC have been used on these projects, neither the equipment performance nor the effectiveness in protecting sea turtles has been documented and released for unlimited distribution.

\section{Objective}

This study was the first step in evaluating TTC as a potential replacement for draghead turtle deflectors. The primary objective of this study, funded by the USACE Dredging Operations and Environmental Research program, was to demonstrate the feasibility for using TTC and to document its operational performance during a hopper dredging project in Kalaeloa Barber's Point Harbor, Oahu, HI. This study was not designed to document the effectiveness of reducing incidental take of sea turtles.

\section{Approach}

The approach used to demonstrate the feasibility for using TTC and document its operational performance is presented in Chapter 2 Approach. 


\section{Approach}

The primary TTC performance metrics to be monitored included assurances that (1) the individual chains hung relatively straight in the water column and maintained quasi-steady spacing between individual chain lengths, (2) the chains did not entangle, thereby creating a drowning risk to turtles, and (3) the chains maintained contact with the seafloor ahead of the draghead while it was on bottom. Operational performance of the TTC was monitored using underwater camera systems over a short period of time whereas the effectiveness for reducing incidental take of sea turtles would require analysis of endangered species observer-monitoring data collected over a longer period than provided in this study. The secondary objective of this study was to demonstrate the feasibility of using underwater cameras for monitoring equipment near or on a draghead during actual dredging operations.

During preparation of the Biological Assessment for the maintenance dredging project to occur during March through April 2016 in five Hawaii commercial harbors, the USACE Honolulu District (POH), in consultation with the National Marine Fisheries Service - Pacific Island Region (NMFS-PIR), determined that endangered species monitoring and standard sea turtle protection equipment and procedures would be required. The five Hawaii harbors included in this dredging project are Nawiliwili, Kauai; Kalaeloa Barber's Point, Oahu; Honolulu Harbor, Oahu; Kahului Harbor, Maui; and Hilo Harbor, HI.

Although the presence of sea turtles is well known for the Hawaiian Islands, dredging is seldom done, and hopper dredging was last conducted in these harbors 17 to 25 years prior to the 2016 dredging. Due to lacking or insufficient data, the need to implement endangered species monitors or additional sea turtle protection measures during these earlier dredging projects was not recognized or required. These needs are now recognized and required as a result of the increase in sea turtle populations or occurrence throughout the Hawaiian Islands and the more recognized risk for incidental take from hopper dredging ${ }^{1}$ (National Marine Fisheries Service 2016). 
The USACE Engineer Research and Development Center (ERDC) has been a leader in developing methods to minimize dredging impacts on sea turtles since 1980 (Dickerson et al. 2004). The POH requested assistance from ERDC to provide the optimal strategy for endangered species monitoring and sea turtle protection specific to the environmental and dredging constraints of the five Hawaii dredging locations. For these recommendations, ERDC included techniques used throughout hopper dredging projects along the U.S. Atlantic and Gulf of Mexico with proven effectiveness for reducing sea turtle takes as well as one technique used outside the United States with unproven effectiveness. Among the recommended protection strategies was a draghead turtle deflector attached to the draghead and TTC attached to the dragarm ahead of the deflector and draghead. A complete description of the sea turtle protection equipment and protocols as well as endangered species monitoring requirements used during the Five Hawaii Commercial Harbors Maintenance Dredging Project is found in the project Biological Opinion (National Marine Fisheries Service 2016).

The draghead turtle deflector was first used during hopper dredging along the U.S. Atlantic coast in 1992 and is typically required by the National Marine Fisheries Service during most hopper dredging projects along the U.S. Atlantic and Gulf of Mexico. The draghead turtle deflector is designed to be buried at least 15 to 20 centimeters (cm) (6 to 8 inches [in.]) into the sediment and to push a wave of sediment ahead of the draghead to potentially stimulate turtles located on or near the seafloor to move away from the oncoming draghead. The performance of the deflector to push this sediment wave was demonstrated during in situ field tests on the dredge McFarland in 1993 with underwater cameras in a clear water environment at Fort Pierce, FL (U.S. Army Engineer Waterways Experiment Station 1997). The effectiveness of the draghead turtle deflector for reducing turtle takes was evaluated after the deflector was implemented for several years and continues to be evaluated.

Based on analysis of over 35 years of dredging-related incidental-take data from endangered species observers, the use of draghead turtle deflectors has resulted in significant reductions in turtle takes (Dickerson et al. 2004; USACE Sea Turtle Data Warehouse 2018 ; USACE Operations and Dredging Endangered Species System 2017). 
Although neither TTC operational performance from underwater monitoring nor equipment effectiveness from turtle-take data analysis is available from dredging projects outside the United States, the TTC concept has merit that should be evaluated for potential turtle protection during U.S. dredging projects. For some of these non-U.S. dredging projects, the TTC were used as the primary turtle protection device (engineering control). If shown to be effective in reducing turtle takes during U.S. hopper dredging projects, TTC may function as the primary turtle protection in lieu of the draghead turtle deflector as it could provide additional turtle protection when the seafloor is uneven and the deflector is unable to maintain constant contact with the seafloor. Sediment type or other environmental conditions may make it extremely difficult or impossible to use a draghead turtle deflector but may be well suited for TTC. The first step in identifying TTC as a possible turtle protection technique is to evaluate its feasibility and operational performance in an in situ dredging environment. The Five Hawaii Commercial Harbors Maintenance Dredging Project was a prime opportunity to conduct such an evaluation.

Prior to arrival in Hawaii, the USACE POH support team and Essayons crew fabricated a rigid design draghead turtle deflector for the Californiastyle draghead and TTC for both the port and starboard dragarms. Figure 1 shows the port dragarm chain array and turtle deflector. The chain array consisted of twelve 3-meter $(\mathrm{m})$ (10-feet [ft]) long sections of $1.3 \mathrm{~cm}$ ( 0.50 in.) transport chains shackled to an L-shaped angle bar of mild steel that was bolted perpendicular to the dragarm approximately $7.6 \mathrm{~m} \mathrm{(25 \textrm {ft } )}$ forward of the draghead turtle deflector. 
Figure 1. Rigid design draghead turtle deflector and $T \mathrm{TC}$ on the Essayons port dragarm (looking aft).

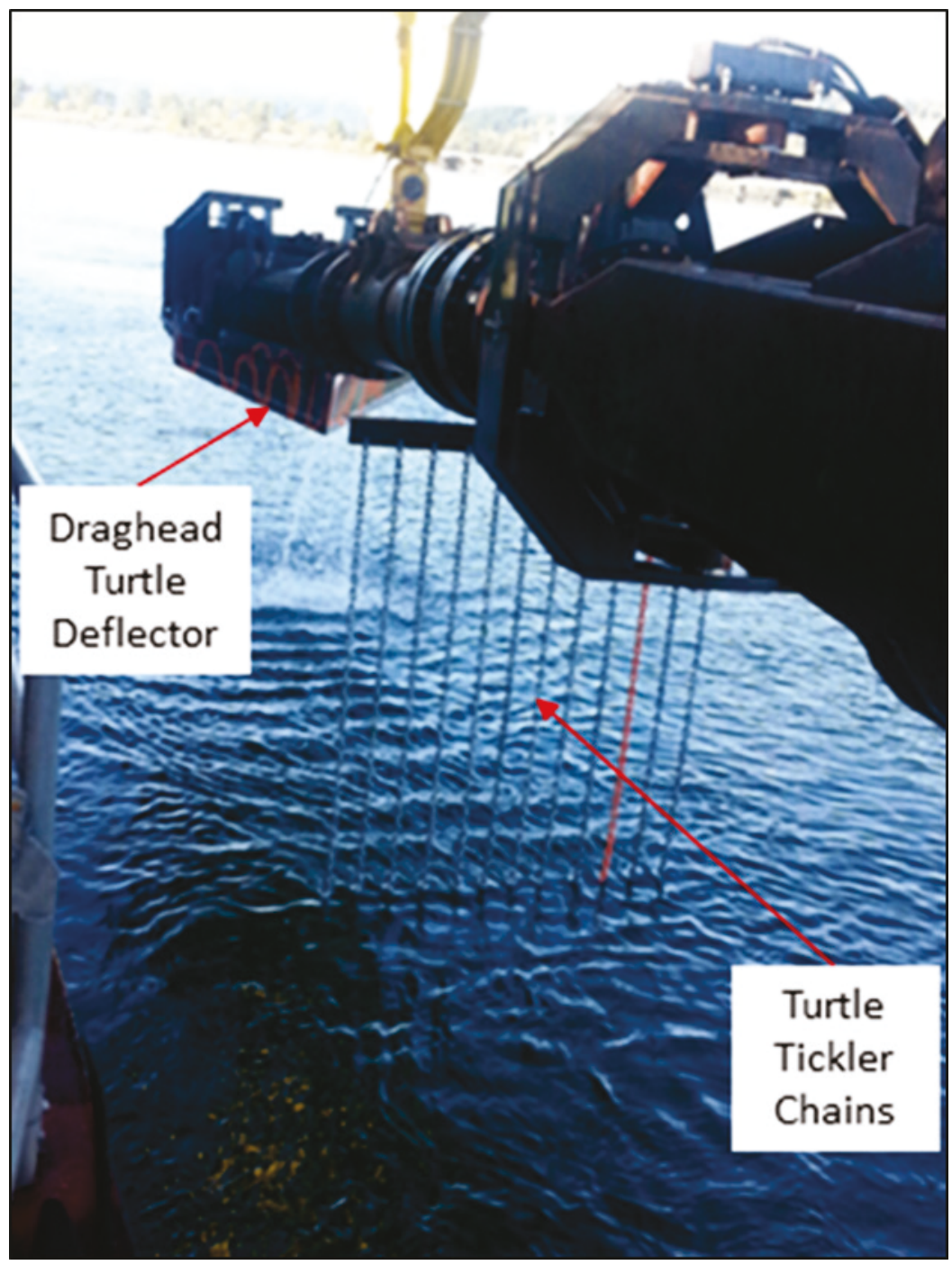

Three types of camera systems were used to evaluate the operational performance of the TTC. The primary underwater operational performance metrics to be monitored included (1) assurance that the individual chains hung relatively straight in the water column to maintain quasi-steady spacing distance between individual chain lengths, (2) did not entangle to create a drowning risk to turtles, and (3) maintained contact with the sea bottom ahead of the draghead while it was on bottom. The three camera systems included the following:

- two GoPro cameras with underwater housings along with a 700-lumen light emitting diode (LED) dive light source (Figures 2 and 3) that are self-recording and require activation before going 
into the water, deactivation after coming out of the water, and provide video subsequently downloaded for viewing

- a high-definition underwater video system consisting of an underwater color camera lens and 2,150-lumen (adjustable) light source connected via a single power/communications cable to a monitoring station on deck (manufactured by Outland Technology) that allowed real-time viewing and recording (Figure 4)

- a 3.0 meghhertz (MHz) high-resolution/high-definition imaging sonar acoustic system (ARIS 3000 acoustic camera manufactured by Sound Metrics) mounted on a pan/tilt rotator assembly with 2 degrees of viewing freedom (Figure 4).

Acoustic cameras, or imaging sonars, are small multi-beam active sonars that are able to visualize turbid environments. They transmit sound pulses into the region of interest and use the returning sound to reconstruct a digital image. The range to the scattering object is determined by the time elapsed between the emission of the sound pulse and the return of the sound scattered by the object (Urick 1983). The direction to the scattering object relative to the camera position is determined by beamforming (or spatial filtering), using the observed lag between adjacent transducers observing the same sound returning to the transducer array to estimate the direction (Van Veen and Buckley 1988). The frequency of the sound pulses transmitted from the acoustic camera partially dictates the operating range of the acoustic camera and the resolution of the reconstructed image. In general, lower-frequency (longer wavelength) sound pulses can penetrate farther into the water column than higherfrequency pulses (shorter wavelength), albeit with reduced spatial resolution in the resulting image. 
Figure 2. GoPro camera in underwater housing and 700-lumen light source mounted on outboard gimbal frame of the dragarm.

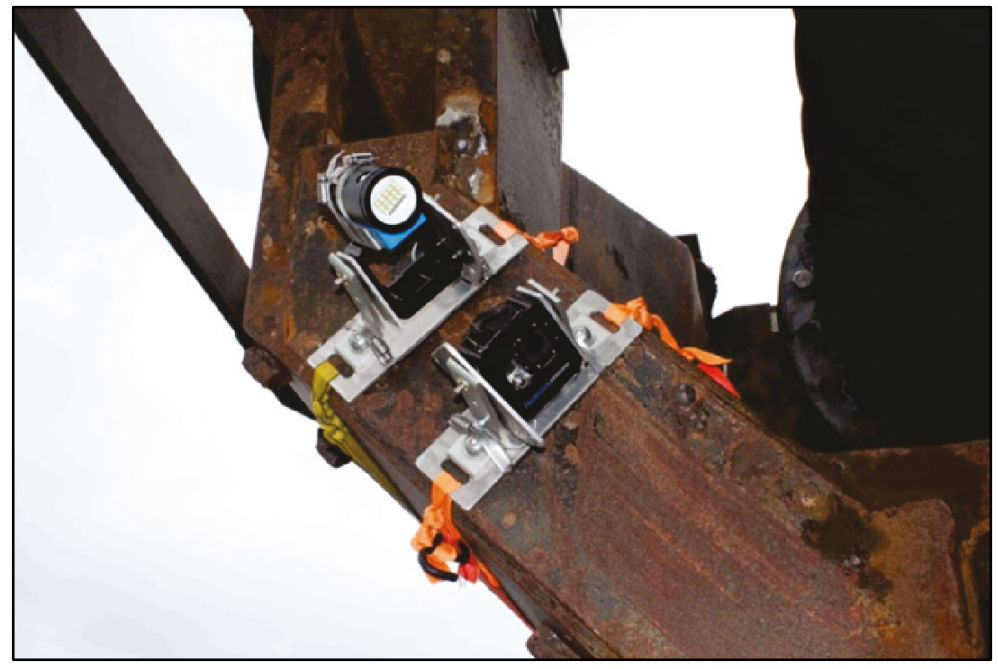

Figure 3. GoPro camera (red arrow) mounted on the dragarm above the chain array.

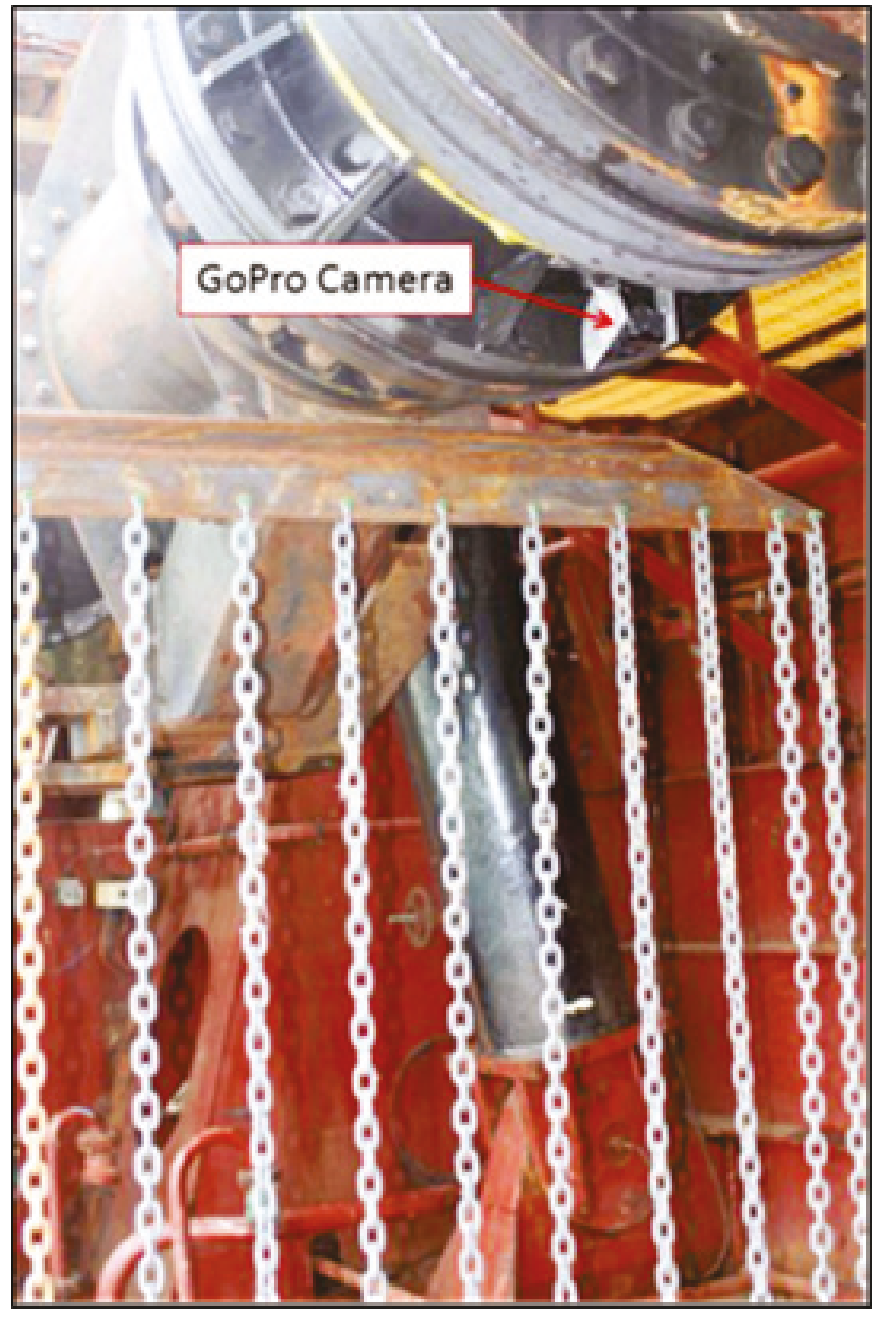


Figure 4. High-definition video camera lens with light and acoustic camera mount.

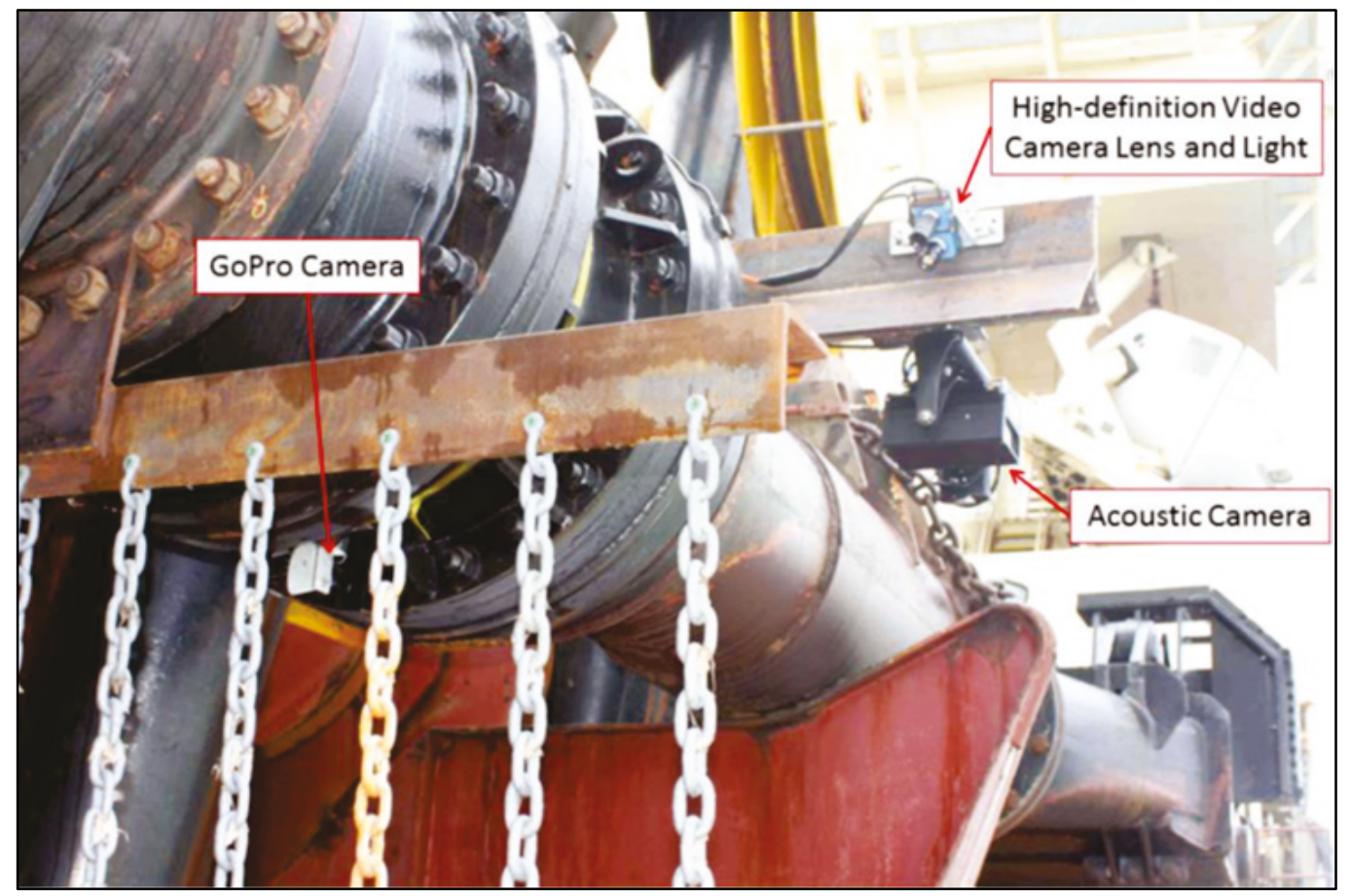

These camera systems were mounted on the Essayons port dragarm while the vessel was in drydock at Mare Island, CA. One of the GoPro cameras was mounted forward of the TTC, and the second one was mounted aft and directly above the TTC with tie-down straps. Figure 2 shows the forward GoPro camera mounted on the outboard gimbal frame of the dragarm along with a 700-lumen LED dive light source on a separate mount. Figure 3 shows the second GoPro camera mounted under the turning gland of the dragarm just aft and directly over the TTC. A special frame was constructed and bolted to the aft flange of the dragarm turning gland to mount the high-definition video system lens and light as well as acoustic camera (Figure 4). The pan and tilt rotator assembly for the acoustic camera, in conjunction with the mount location on the dragarm, allowed this camera to be remotely operated and to view either the TTC or the draghead. The power and communications cables of the high-definition video system and acoustic camera were attached to the dragarm pipe and frame and run into a deck space below (i.e., the boatswain locker) where they were connected to the video monitoring and data recording computers (Figure 5). Two-way radios were used to maintain communication with the ship's bridge and the dragtender during all video monitoring of the tickler chains and deflector with the camera. 
Figure 5. Underwater video and acoustic camera systems viewing and recording station in the boatswain locker.

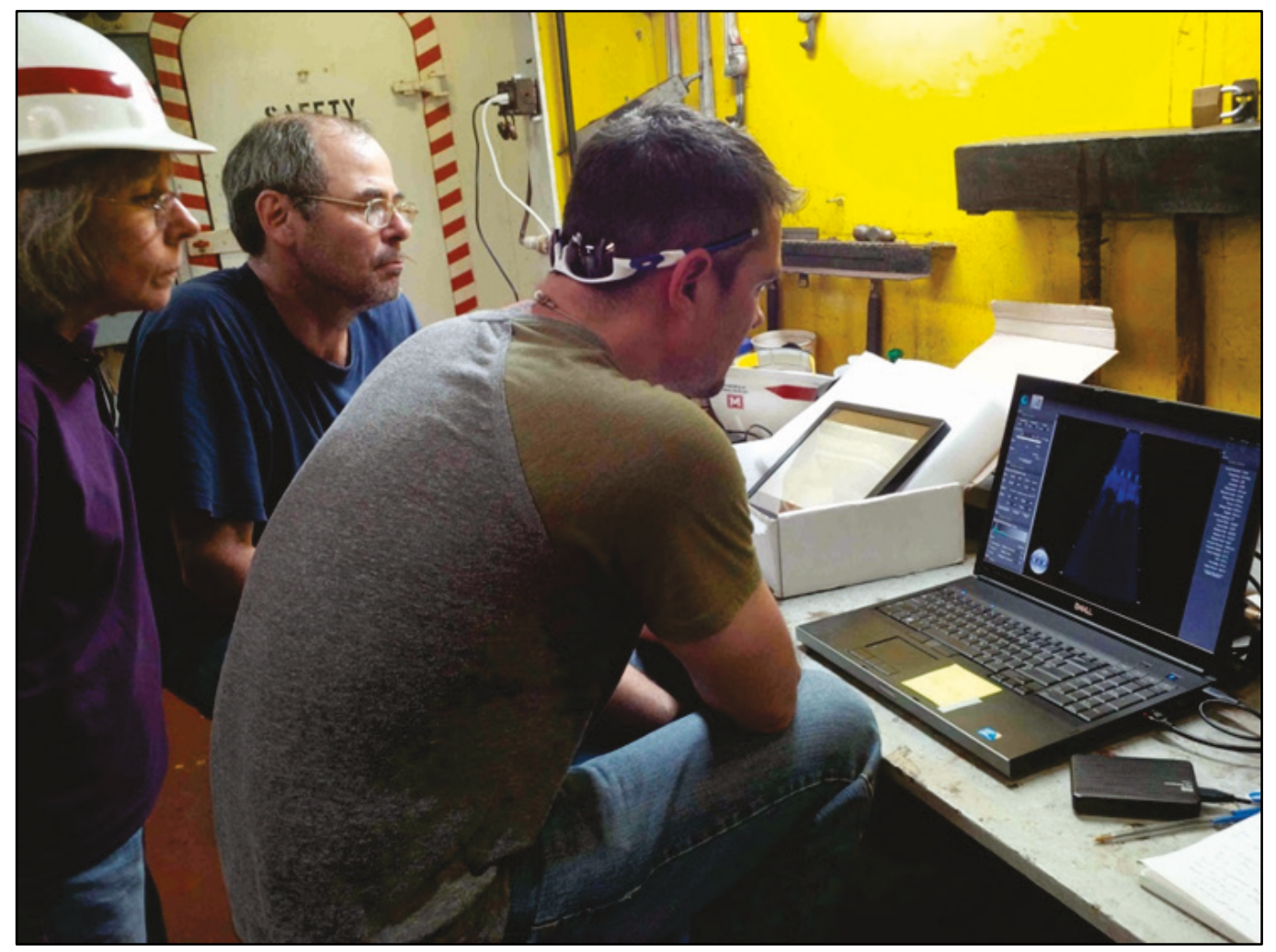

After leaving drydock at Mare Island, CA, the dredge Essayons conducted limited test dredging trials in the San Francisco Bay Pinola Shoals on 3 March 2016 before departing for Hawaii. These short test dredging trials allowed the camera systems to also be tested prior to arriving in Hawaii and provided valuable preliminary videos for approximately 15 minutes of the TTC and the draghead turtle deflector.

Although the dredge Essayons began dredging in Hawaii at Nawiliwili on 14 March 2016, the TTC could not be used because of unexpected equipment and logistical issues, and therefore underwater camera monitoring could not begin until 24 March 2016 when the dredge reached Kalaeloa Barber's Point, Oahu. The TTC and cameras were removed during dredging at Nawiliwili, but the steel angle mounting brackets were left on the dragarm. During the dredging at Nawiliwili, the brackets installed in Mare Island to hold the TTC as well as the acoustic camera mount sustained substantial damage (Figure 6). 
Figure 6. Damage to portside chain bracket and acoustic camera mount.

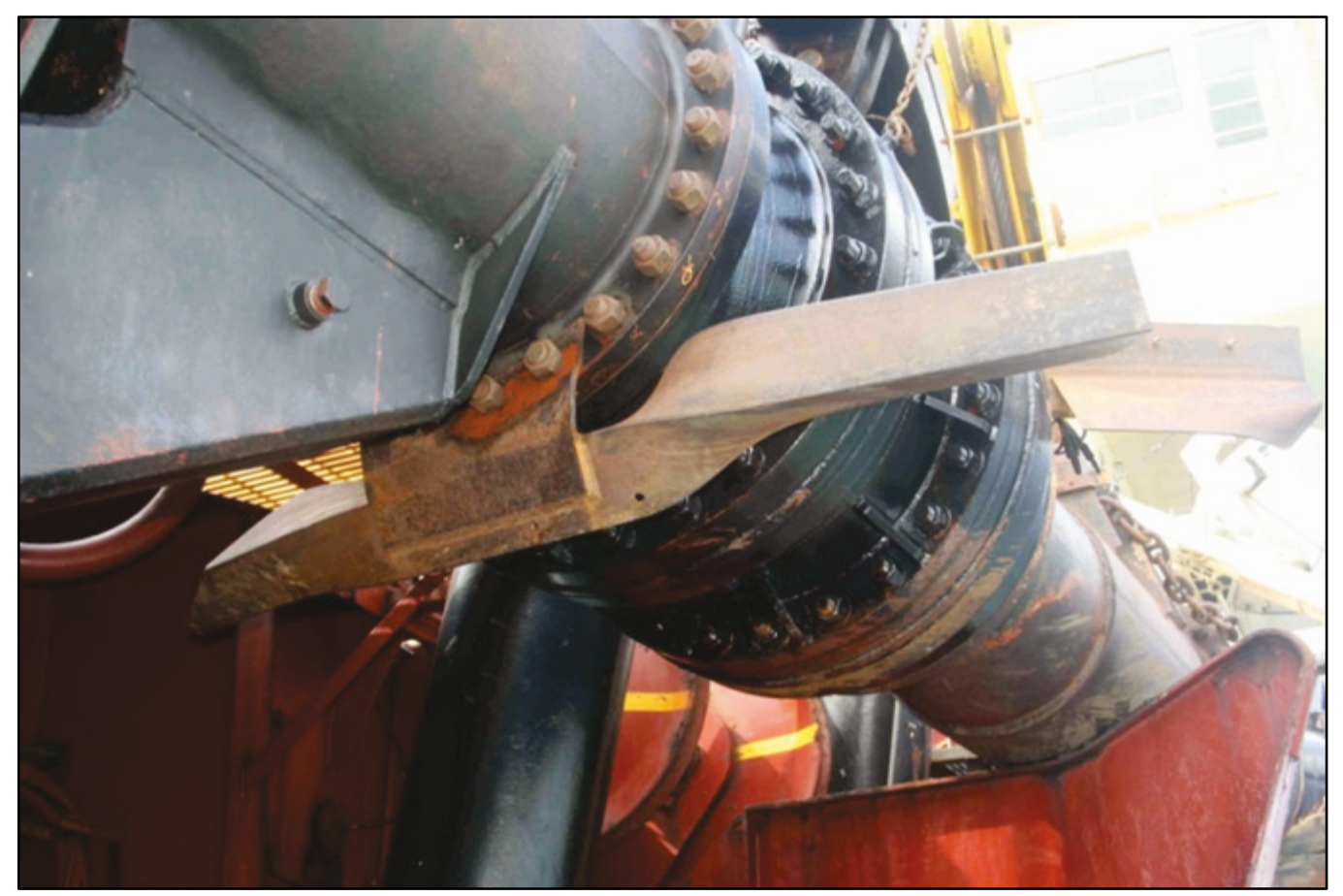

The port TTC bracket had to be replaced before the chains could be attached, and only the acoustic camera could be attached to the bent camera mount. Because the high-definition video camera lens and light could no longer be bolted to the bent mount without significant repair effort and lost dredging time, a GoPro camera mount was modified and used to mount the high-definition camera and light on the aft frame of the dragarm gimbal (Figure 7). Figure 8 provides a different perspective of the mounted positions for the GoPro camera and high-definition camera systems relative to the chain array and draghead, which were deployed during the Kalaeloa Barber's Point testing. 
Figure 7. Revised camera and light mount configuration (aft looking forward) for Barbers Point, HI.

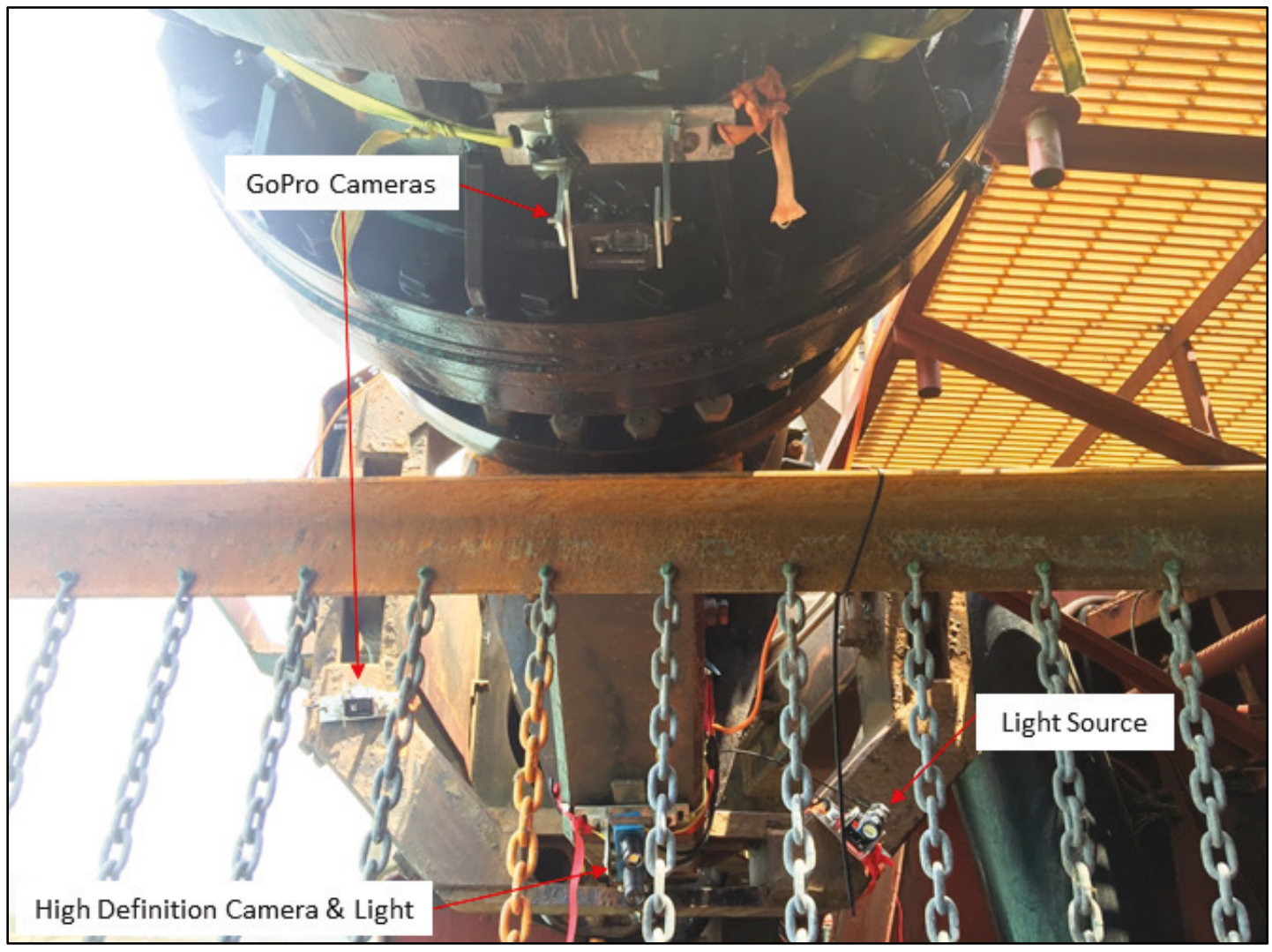

Figure 8. Profile view of revised positions for the three camera systems relative to TTC and draghead (Kalaeloa Barbers Point, $\mathrm{HI}$ ).

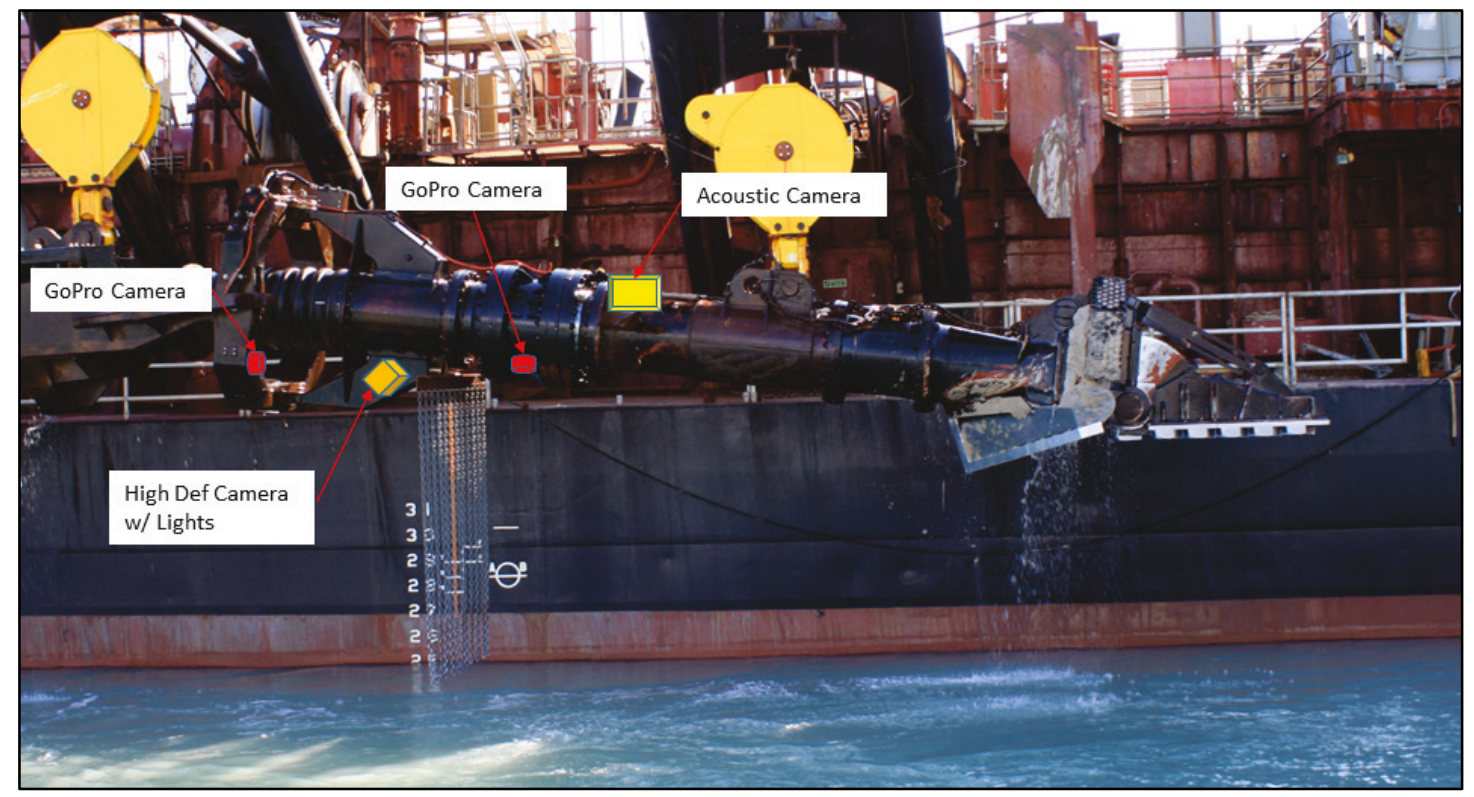


The acoustic camera rotator assembly was mounted to the turning gland mount bracket by a single 8-millimeter bolt; therefore, a tie-down strap was used to also secure the camera gimbal to the dragarm. Once the Essayons arrived at Kalaeloa Barber's Point on 24 March 2016, camera systems and TTC were immediately reinstalled. Real-time monitoring and video recording were conducted on the TTC and draghead turtle deflector with the acoustic camera and high-definition camera during the first 2 hours of dredging (between 1400 and 1600 hours) on 24 March 2016. Simultaneous underwater video recordings were made with the GoPro cameras during dredging. Data from the GoPro cameras were not viewed in real time and were retrieved from the camera data card after the dragarm was cradled on deck.

\section{$\underline{\text { Kalaeloa Barber's Point Test \#1 }}$}

The first test conducted at Kalaeloa Barber's Point consisted of observing the TTC during normal dredging operations with the optical (Go Pro and high-definition) and acoustic camera systems. After a few minutes of dredging, the camera equipment became submerged in the predominantly fine-grained (muddy) shoal material because the bottom was so unconsolidated and the draghead easily penetrated the harbor bottom. Immediately after the live camera feed went black, the dragtender was instructed to pull the dragarm up, and the camera systems were inspected and cleaned. No damage was found to any of the equipment. The risk of damaging or losing the expensive acoustic camera system in the mud became a paramount concern in the following tests, and draghead depth relative to bottom elevation was monitored closely.

\section{$\underline{\text { Kalaeloa Barber's Point Test \#2 }}$}

For the second test, the dragtender kept the draghead at the existing bottom depth as indicated from recent survey records. By skimming the draghead on the bottom, rather than immersing the lower drag pipe, the camera equipment was less at risk for damage from sediment impact. The dragtender also set the lower dragarm angle to maintain the correct positioning of the draghead turtle deflector in the sediment. 


\section{$\underline{\text { Kalaeloa Barber's Point Test \#3 }}$}

The objective of the third test was to verify if the images from the acoustic camera were discriminating enough for a person to observe entangled or damaged tickler chains. Therefore, several of the chains were tied together using electrical wire ties at several different lengths on the chains. For the first part of this test, the draghead was held in the water column, with the pumps turned off, to allow observation of the acoustic images of the trailing bound chains. For the second part of this test, the draghead was lowered to the sea floor with the prescribed lower dragarm angle and the pumps turned off. 


\section{Results}

\section{Preliminary test in San Francisco Bay, California}

Because of the in situ water turbidity, quality of the videos collected with the GoPro camera and the high-definition camera systems during the limited test dredging trials was marginal. Conversely, the quality of video collected by the acoustic camera allowed evaluations of detailed images due to the much higher level of detection and discrimination provided by this system. This quality allowed the viewer to discern the performance of the TTC in the water column and its interaction with the sand waves on the sea bottom (Figures 9 and 10). While a sense of perspective (acoustic camera position relative to the object being viewed) can allow the viewer to perceive a more meaningful interpretation of what is being viewed, some acoustic camera images are not a direct analog of a conventional photograph. The point cloud of acoustic returns (at $3 \mathrm{MHz}$ ) allows the system operator to mathematically rotate the image being ensonified, in real time or post processing. While Figure 8 presents the physical object location relationships of the acoustic camera to the TTC and turtle draghead deflector, Figures 9 and 10 of the TTC have been mathematically rotated. Note that viewing the video (as opposed to still images taken from the video as shown in this report) provides a more complete sensory interpretation of what is being viewed.

The acoustic camera image in Figure 9 demonstrates this system's resolution by being able to discriminate individual $1.3 \mathrm{~cm}$ (0.50 in.) diameter links in the chain sections and by detecting a fish of unknown species swimming between two of the chain sections. However, due to the acoustic camera's grazing angle and distance to the chains, it was not possible to view the entire $3 \mathrm{~m} \mathrm{(10} \mathrm{ft)} \mathrm{lengths} \mathrm{of} \mathrm{all} \mathrm{the} \mathrm{chains} \mathrm{at} \mathrm{the} \mathrm{same}$ time. The rotator assembly had to be used to tilt the transducer array to scan from the top of the chain mount down to the chain ends. Use of the rotator assembly's panning capability allowed the camera to be swung around aft to view the draghead and turtle deflector. Figure 11 shows an acoustic image of the draghead and turtle deflector in sandy bottom material (this image was not mathematically rotated). These preliminary tests provided valuable information and experience to optimize operation of the camera systems for the main testing during the dredging in Hawaii. 
Figure 9. Acoustic camera image of $\Pi \mathrm{TC}$ free-streaming in water column over sand waves.

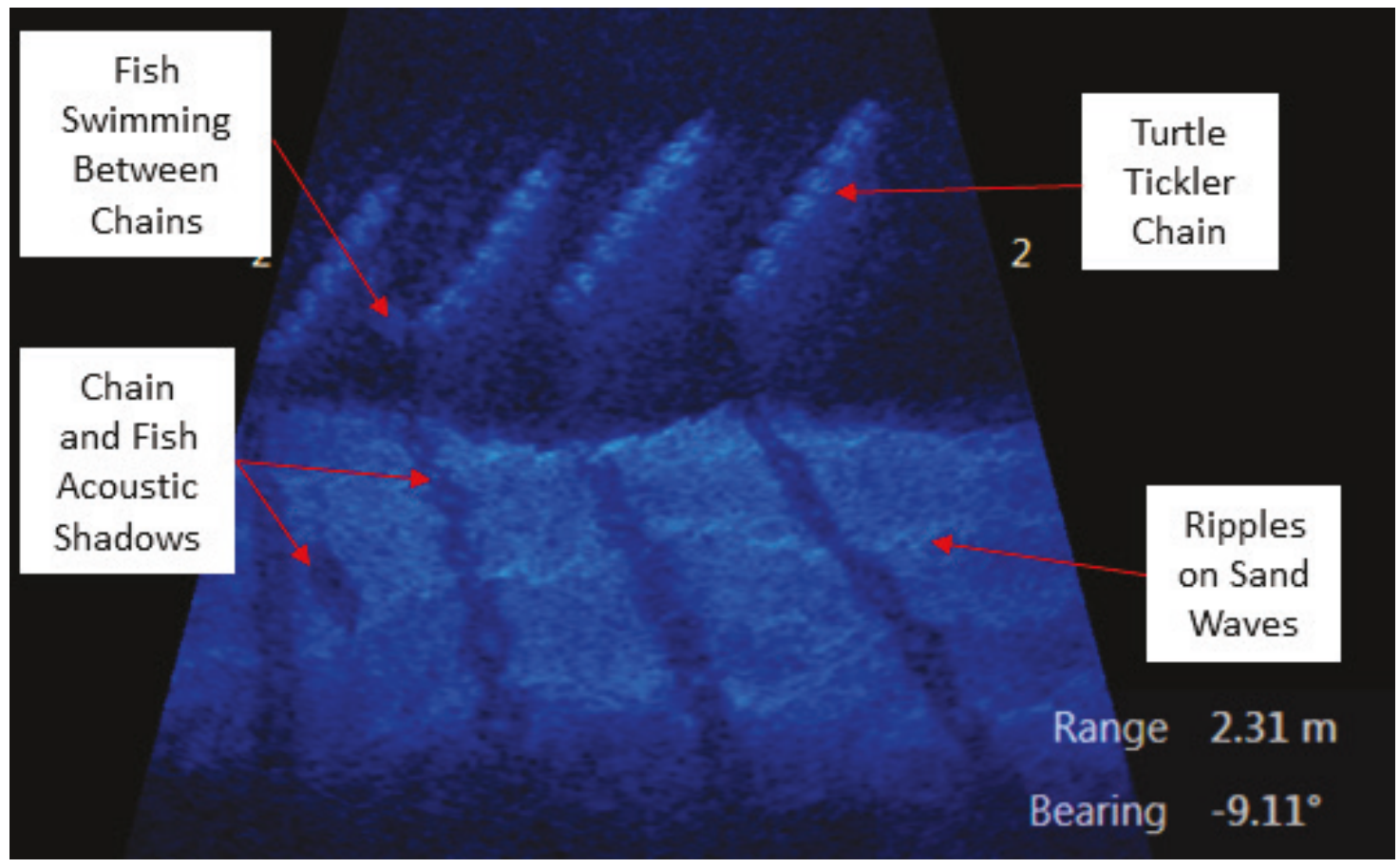

Figure 10. Acoustic camera image of tickler chains dragging over sand bottom.

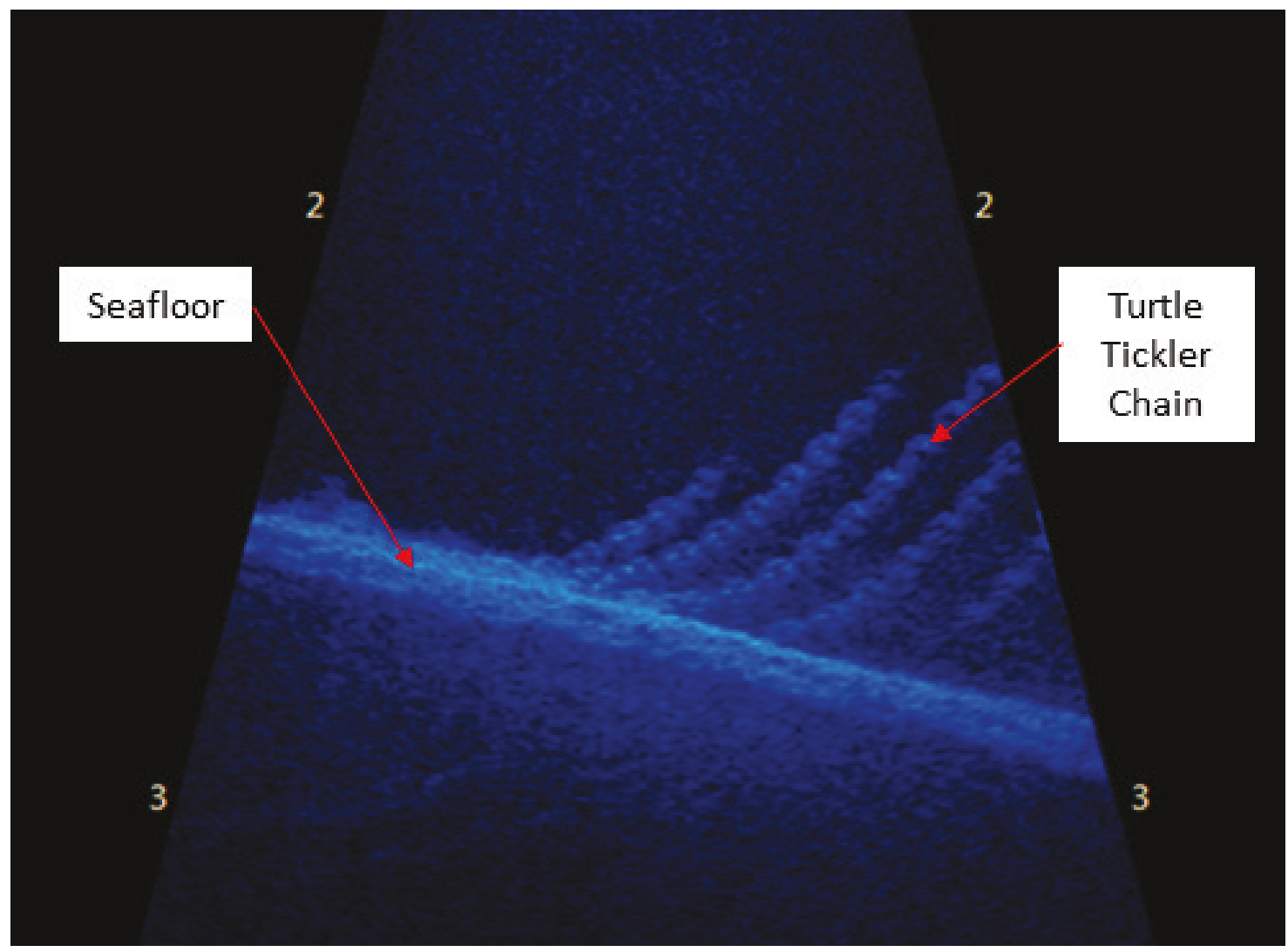


Figure 11. Acoustic camera image of the draghead interacting with sand wave crest.

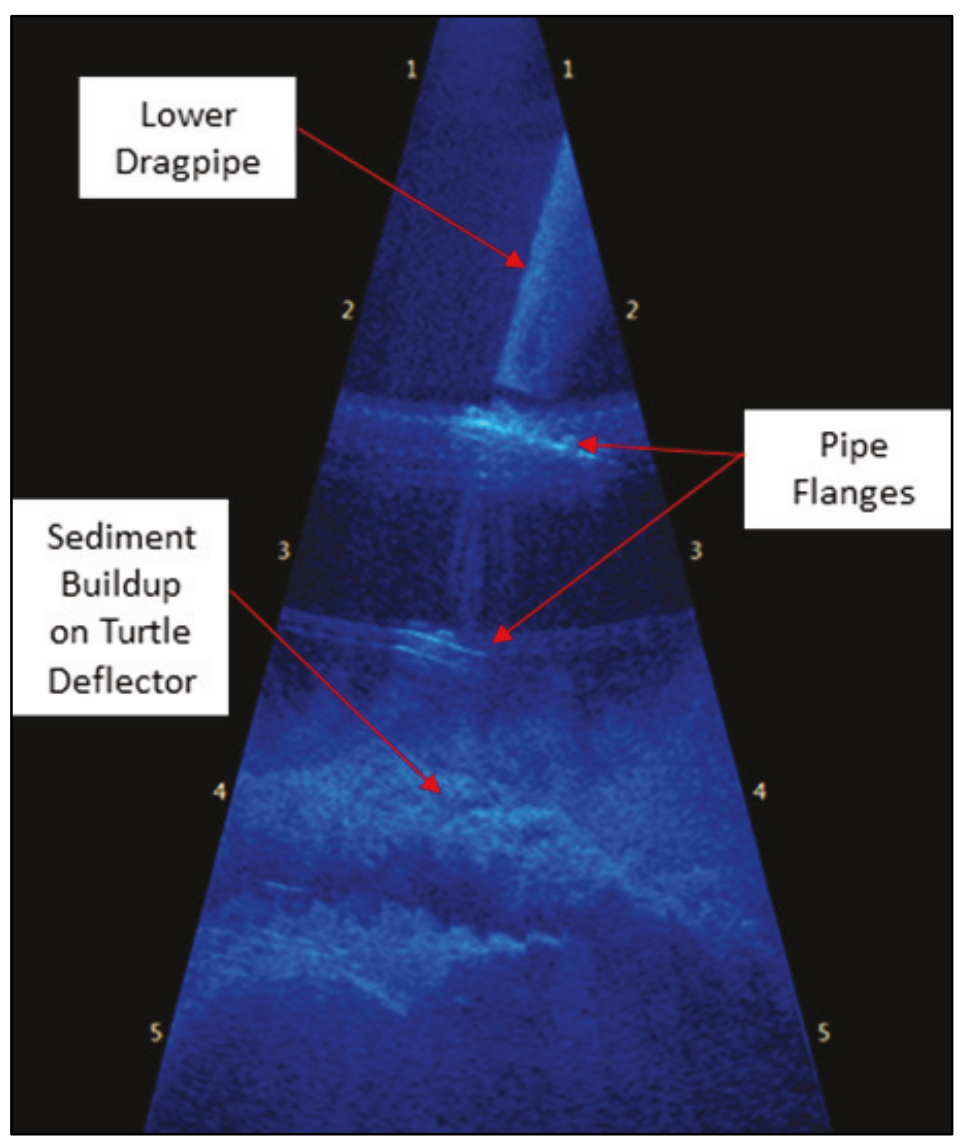

\section{Testing at Kalaeloa Barbers Point, Oahu, HI}

\section{High-definition camera}

Water visibility in the harbor at Barbers Point limited data quality collected by the high-definition camera. While video recording with this camera system, as well as the GoPros, was initiated as soon as the dragheads went into the water, bottom sediments were already being resuspended by the propeller wash from maneuvering the Essayons in the harbor. The initial images viewed real time from the high-definition camera showed the chains and seafloor (Figure 12), but the image quality quickly degraded once the resuspended sediment concentrations increased as the dragheads were dragged through the bottom sediment and propellers and bow thruster rotated. Data quality for the high-definition camera was further impacted by the inability to pan or tilt the camera lens to follow areas of interest (e.g., point of contact with sediment) as the relative position of the chains (to the camera field of view) changed as a function of height above the sea bottom. While light intensity of this 
system was varied to optimize data quality, once the higher resuspended sediment plumes were encountered, the higher-intensity light settings only created a white out screen (e.g., high beam car lights in a snow storm at night). The position of the high-definition camera was not able to allow for viewing of the draghead turtle deflector during these tests.

Figure 12. Image of video collected by the high-definition camera system showing chains dragging along the harbor sea bottom.

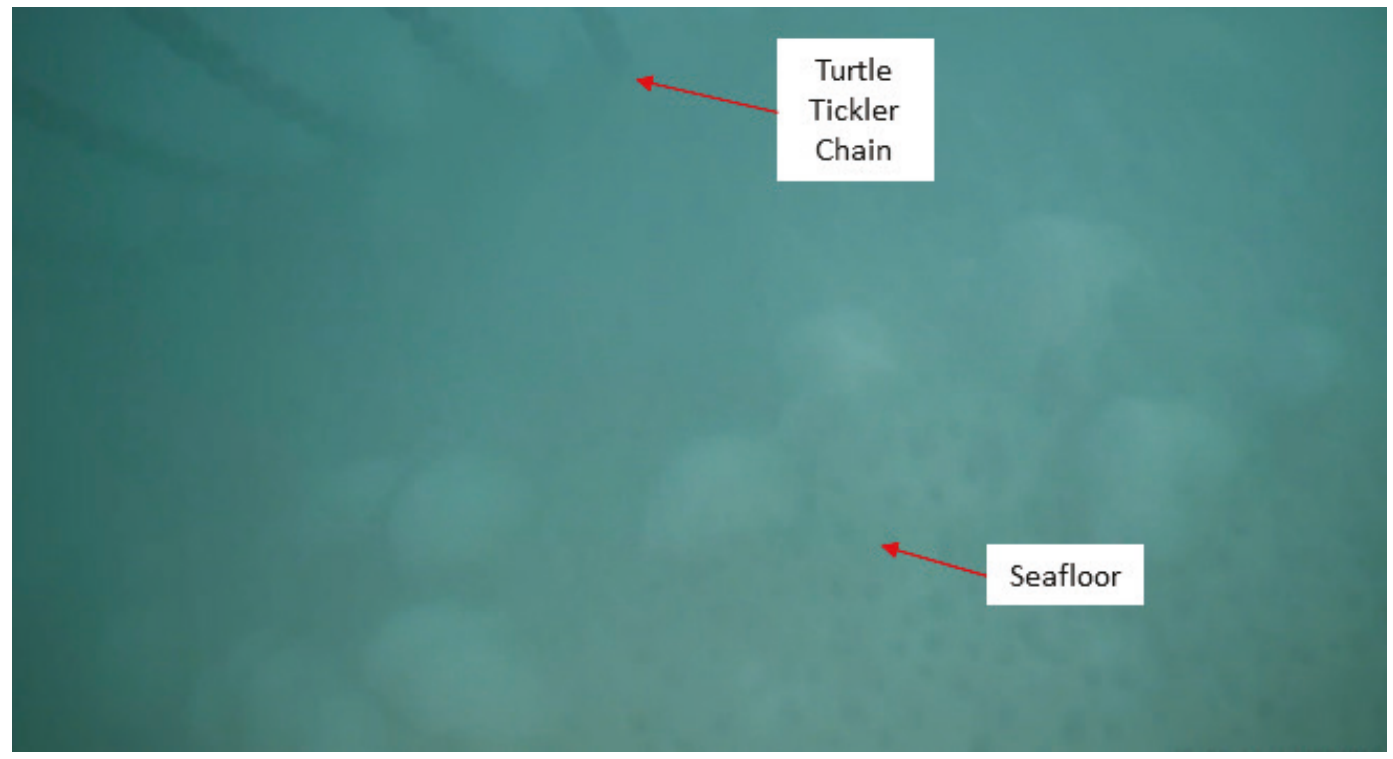

The real-time camera output allowed the operator to identify when the camera lens was immersed in the bottom sediment. The unconsolidated shoal material consisted of fine sand (composited samples ranging from $27 \%$ to $8 \%$ ), tan clay (50\% to $5 \%$ ), and silt (30\% to $1 \%$ ) and provided such a low bearing strength that the draghead could easily penetrate down into the sediment. During one of the initial test runs, the sea bottom could be observed as it got closer to both the high-definition and the acoustic camera lens before both screens blacked out. When this occurred, the camera operator notified the dragtender via radio to immediately bring the dragarm up and out of the water to minimize risk of damaging the cameras and to check the camera for damage (no damage was observed). Figure 13 shows the dragarm as it looked when brought to the surface and illustrates how the draghead and lower dragarm could be immersed into the unconsolidated bottom sediment and potentially be damaged. 
Figure 13. The Essayons draghead and lower dragpipe covered in sediment.

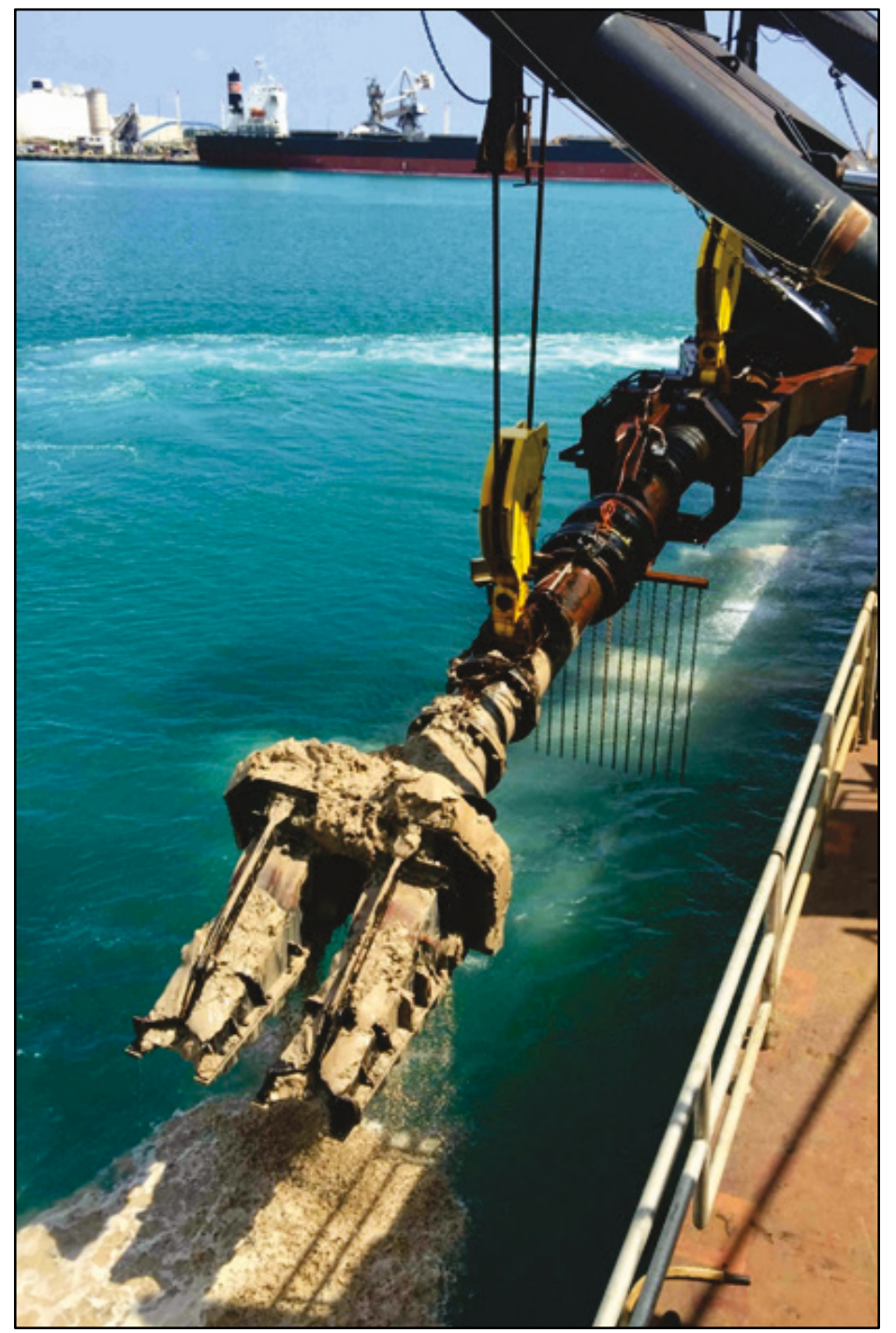

\section{GoPro cameras}

Video from the GoPro cameras, similar to the high-definition camera, suffered from the limited water visibility and fixed field-of-vision orientation relative to the chains. The GoPro camera mounted on the dragarm gimbal yielded limited viewable images due to its distance from the chains and less-than-optimum positioning while the GoPro camera attached to the bottom of the turning gland produced the best video when the top of the chains was closest to the top of sediment (Figure 14). 
Figure 14. Image of the chain array from the GoPro camera on the bottom of the dragarm turning gland.

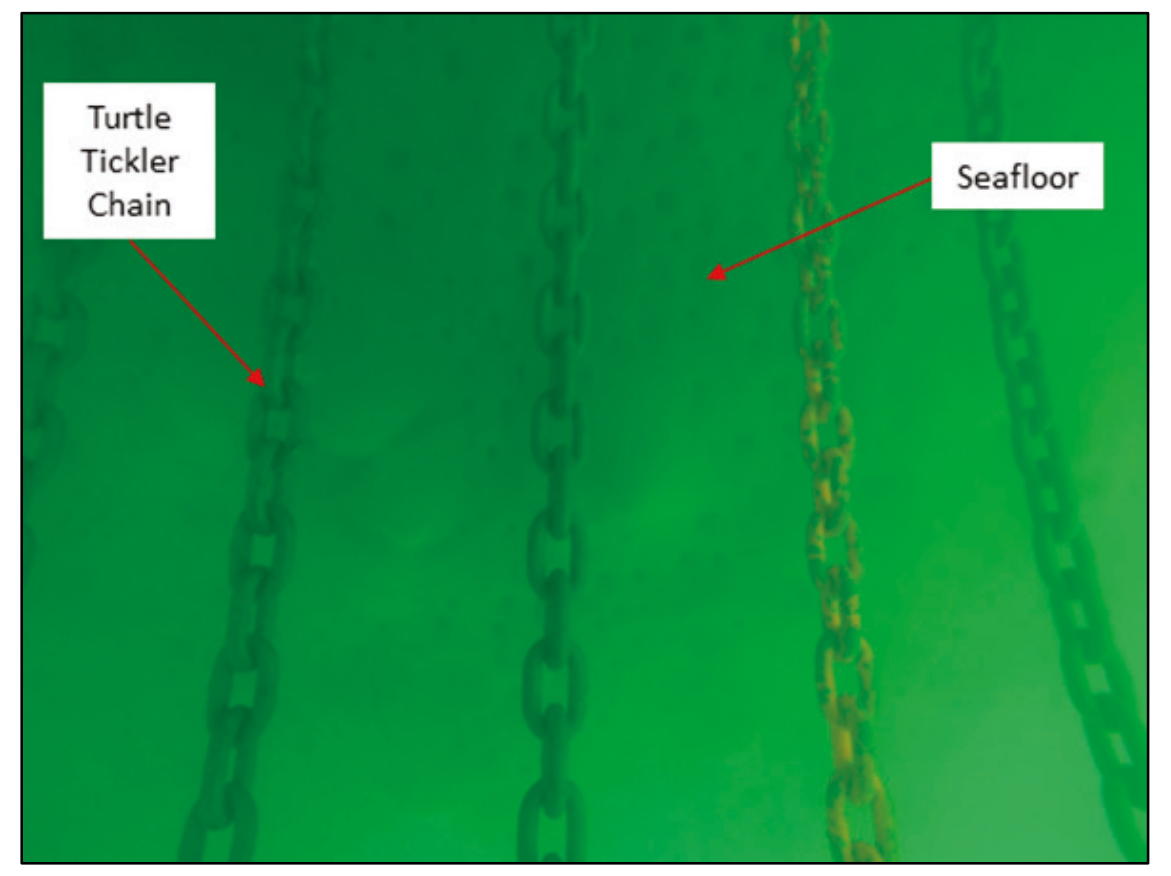

\section{Acoustic camera}

Since the acoustic camera was on a pan and tilt mount, it could be adjusted remotely while dredging was in progress to view either the TTC or draghead. Even with the turbid water and mechanical vibrations during dredging, the acoustic camera was able to provide relatively clear images of the TTC, draghead, turtle deflector, seafloor, and sediment movement.

\section{Turtle tickler chains (TTC)}

When the TTC were suspended in the water column as the dredge moved, the acoustic camera images clearly showed the individual chains hanging down from the dragarm and not becoming entangled. Figure 15 shows the TTC immediately suspended off the harbor bottom. Due to the acoustic camera's grazing angle and distance to the chains, it was not possible to view the entire $10 \mathrm{ft}$ lengths of all the chains simultaneously. The rotator assembly was required to tilt the acoustic camera to scan from the top of the chain mount down to the chain ends. When the draghead was on bottom, the TTC maintained contact with the seafloor, did not entangle, and maintained a relatively constant separation distance between individual chain lengths (Figure 16). While the chains maintained a relatively constant separation distance from each other when dragging in the seafloor (Figure 16), it was noted that range of horizontal and vertical motion was larger in 
the soft bottom material compared to that while in sand. Note that the video (as opposed to still images taken from the video shown here) provides a more complete interpretation of what is being viewed.

Because the high-definition and GoPro cameras were not able to provide adequate images throughout the entire monitoring period due to the turbidity in the water, assessment of TTC performance relied primarily on images provided by the acoustic camera. As the previously presented images relate, these images provided clear viewing of the chain array in the water column and while dragging along the bottom. The images were clear enough to identify distinct links in the chain and sediment movement from the chains. Occasionally, an image of an unidentified fish could also be seen.

Figure 15. Acoustic camera image of chains free-streaming in water column above the harbor bottom.

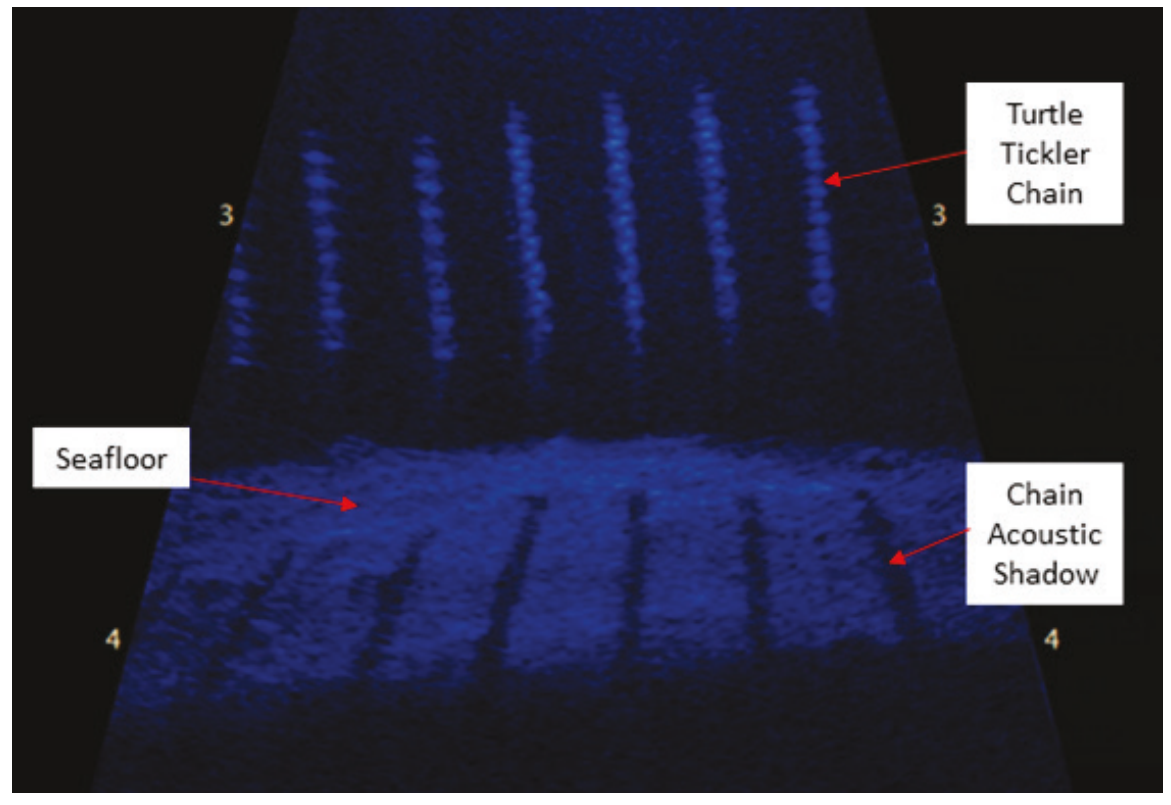

When the tickler chains were bound with electrical wire ties to evaluate the acoustic camera's ability to discriminate a potential chain entanglement that could pose a drowning risk to turtles, these tie points could be clearly and easily identified in the acoustic camera images. Figure 17 shows a comparison of a photograph of the bound chain array out of water with the acoustic camera image of the bound chain array free-streaming in the water column. 
Figure 16. Acoustic camera image of chains dragging on harbor bottom.

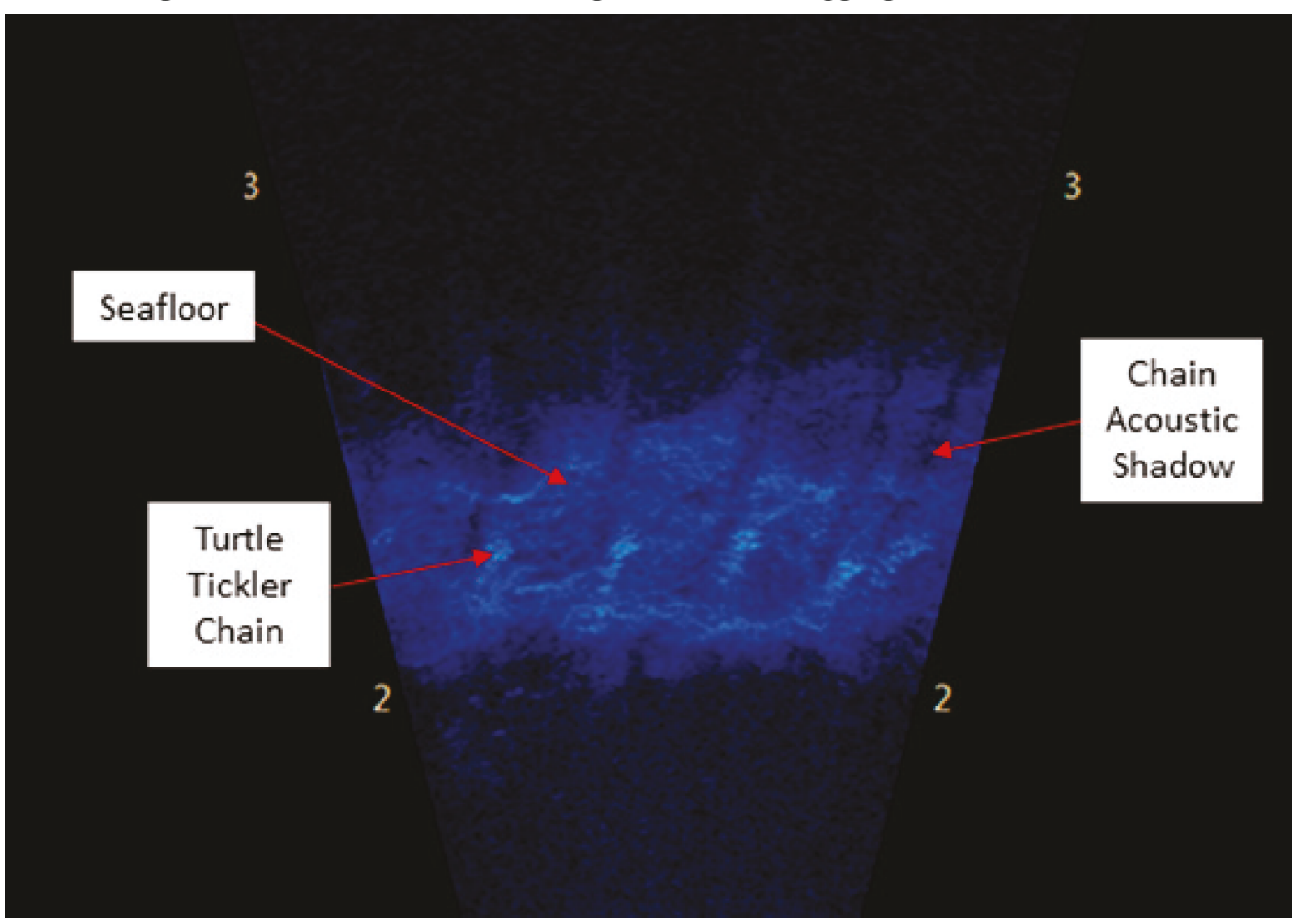

Figure 17. Photograph (left) of the bound chain array out of the water compared to the acoustic camera image (right) of chains free-streaming in the water column.
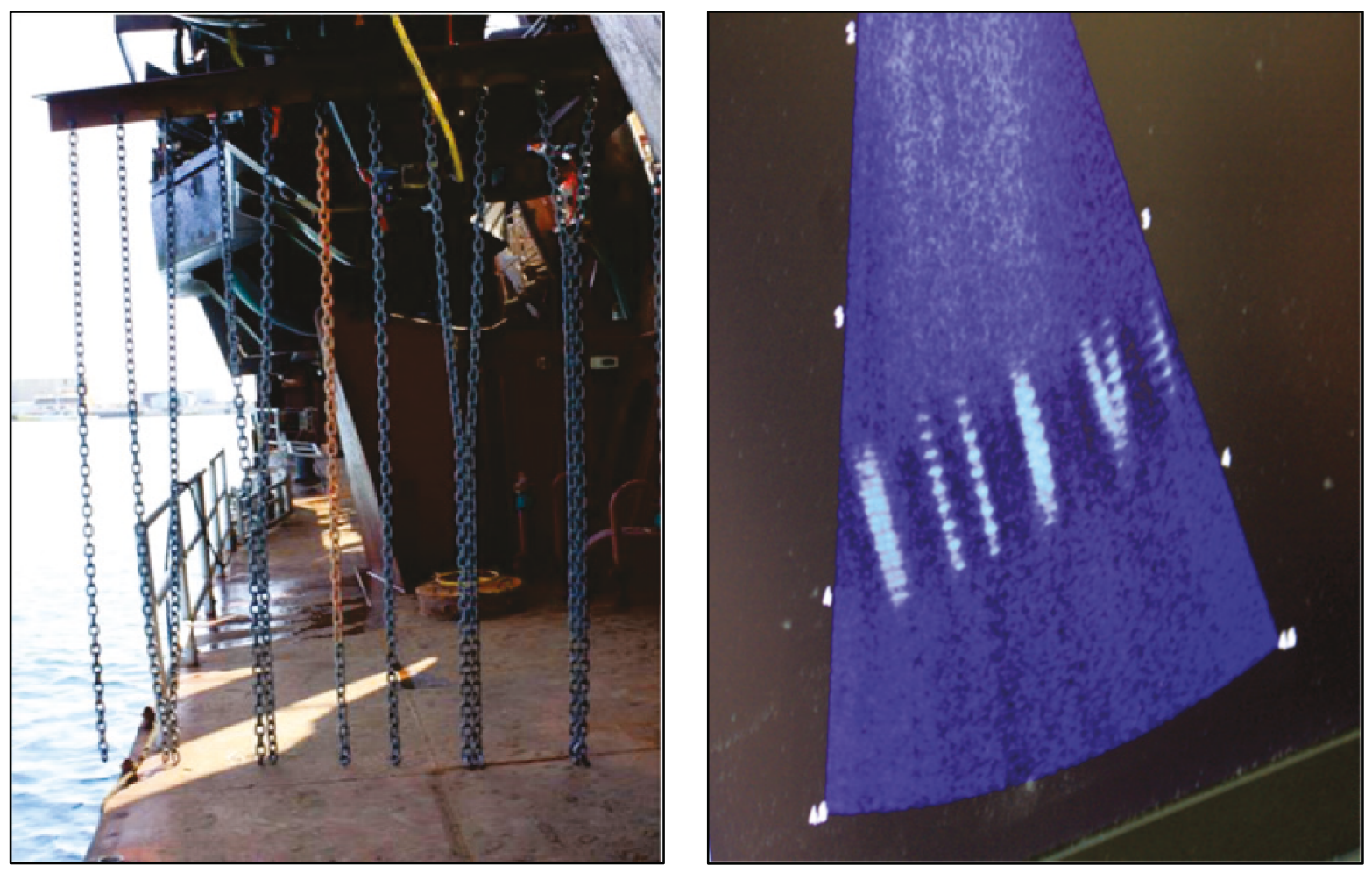
The chain binding locations could be identified in the acoustic image by observing where the chains were angled and no longer parallel and the image formed a notably large signal return. It was observed that the motion behavior of the bound chains was slightly different than that of the unbound chains.

The acoustic camera images were also able to provide detailed representation of the sea bottom texture. Figure 18 shows an image of the sea bottom from the acoustic camera, which has the same mottled pattern seen of the sea bottom from the high-definition and GoPro cameras (Figures 12 and 14, respectively).

Figure 18. Acoustic camera image of the sea bottom.

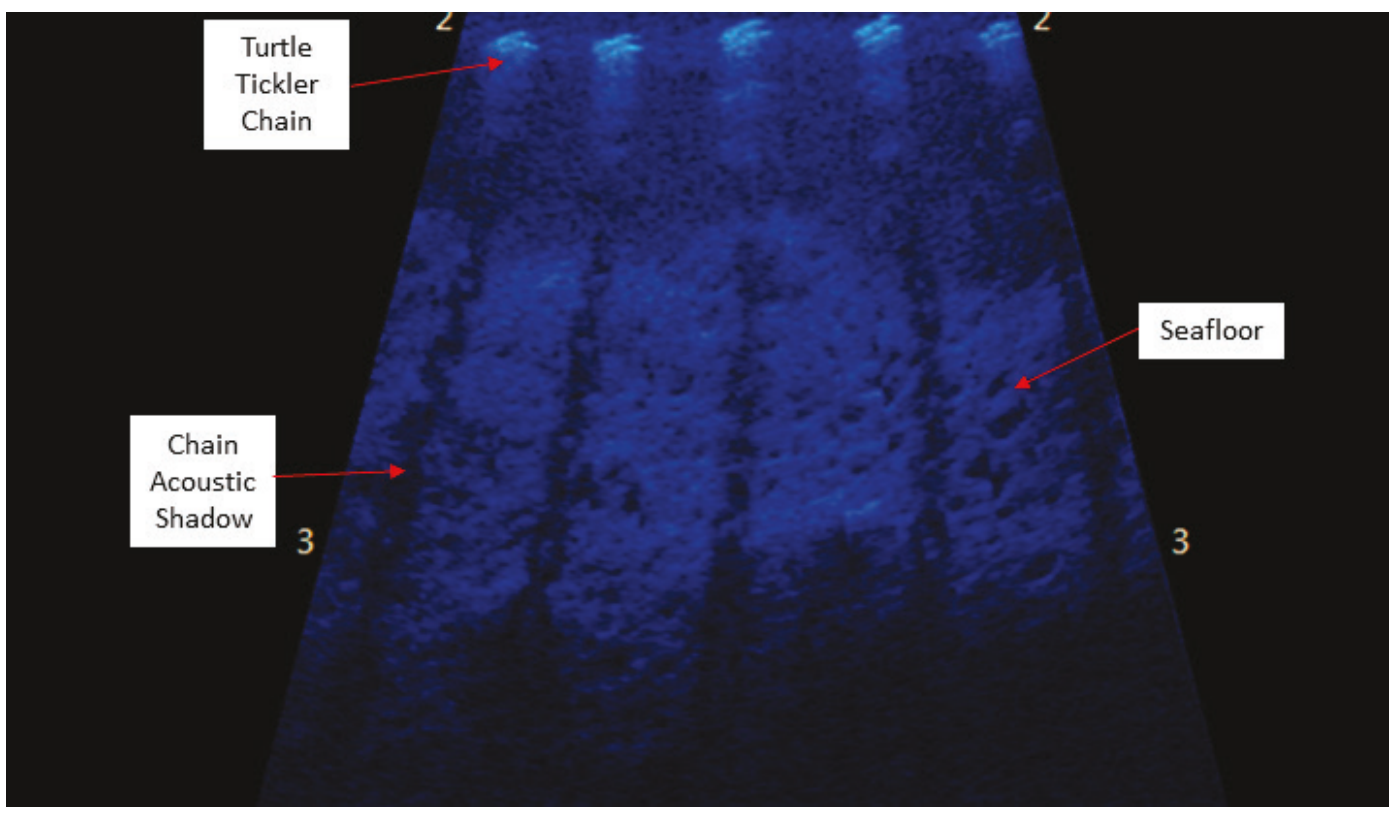

\section{Draghead turtle deflector}

The primary objective of this study was to assess the operational performance of the TTC, so the acoustic camera was mounted and positioned to optimize that objective. Because of the ability to adjust the acoustic camera with the pan and tilt mount, a view of the forward end of the draghead and turtle deflector was also possible during the test. Figure 19 shows these features while the dragarm was suspended in the water column with the leading edge of the turtle deflector seen as a predominant feature. Figure 20 is an acoustic image of the draghead on the bottom, and a sediment wave can be clearly seen building up in front of the draghead as it is plowed through the sediment. The high-definition and GoPro cameras 
were unable to view the deflector due to turbidity and the position of the cameras. The acoustic camera was able to clearly confirm that the draghead deflector was positioned correctly to create the needed sediment wave forward of the draghead to potentially move sea turtles away.

Figure 19. Acoustic camera image of the draghead with turtle deflector in water column.

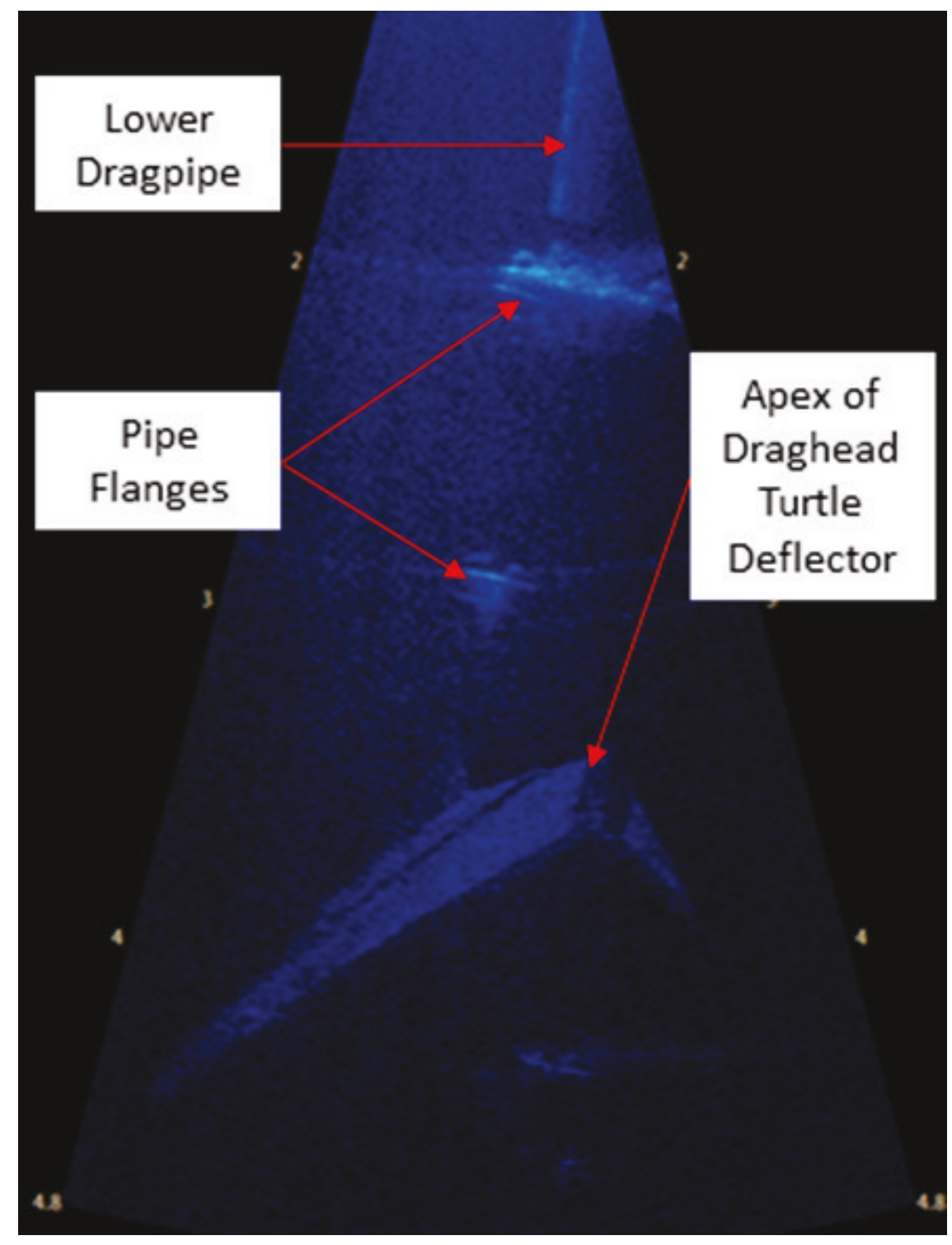


Figure 20. Acoustic camera image of the draghead in mud with a sediment wave building up on turtle deflector.

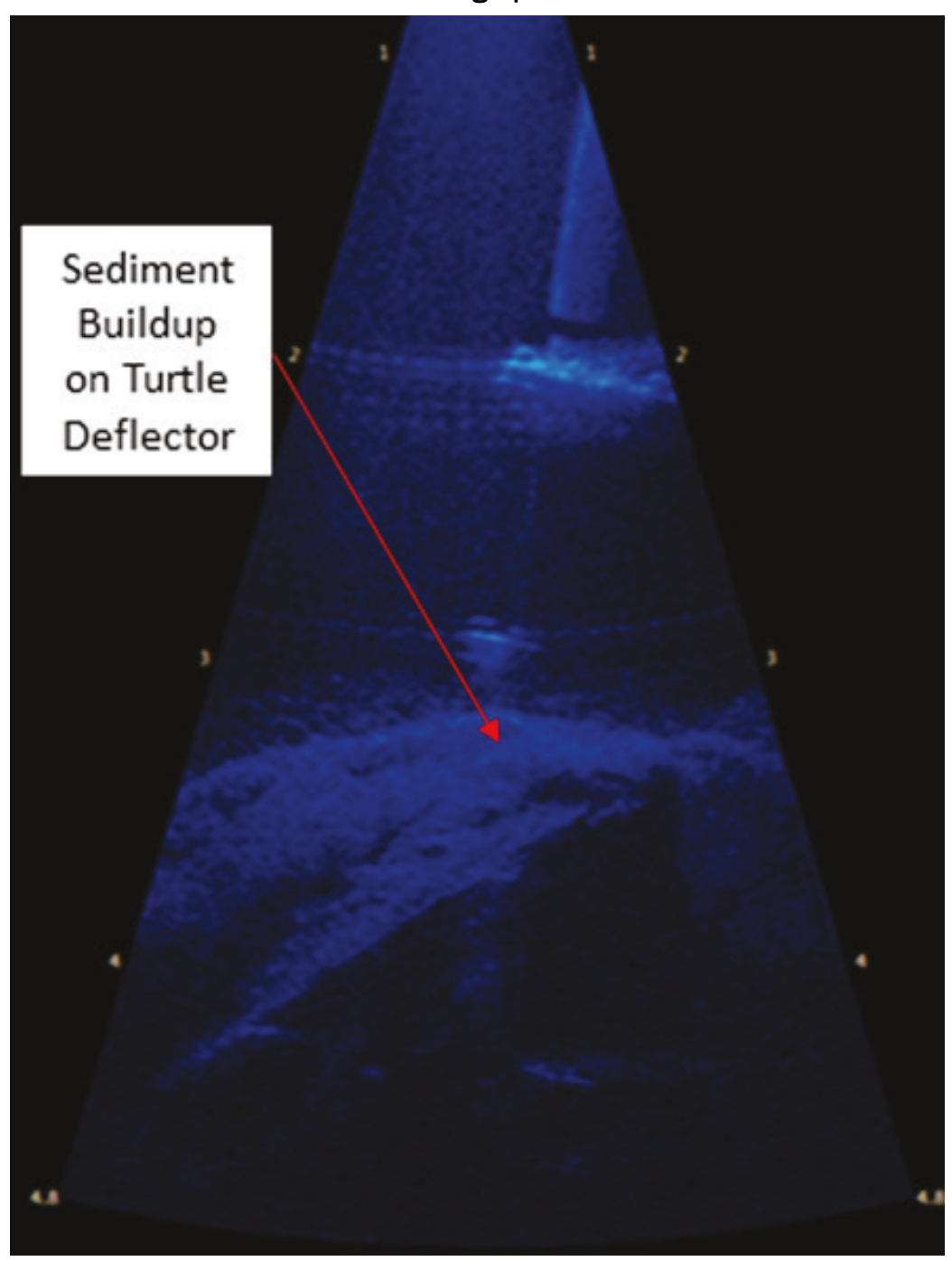

The period of performance for the cameras mounted on the dragarm was only intended to be for the short duration of this study. Due to the vulnerability of the camera mounts and cameras being damaged or lost, particularly the acoustic camera, all camera systems were removed at the end of the monitoring period on 24 March 2016. The cameras were not used for monitoring during the remainder of the dredging project. As requested by NMFS-PIR in the Biological Opinion, the TTC were left attached to the dragarms and were to remain for the duration of the project unless there was evidence of damage to the chain structure or a change in its performance. For the remainder of the dredging project, the endangered species observers inspected the chain arrays for damage after each dredge load (Figure 21). 
Figure 21. Endangered species observer inspecting condition of TTC after dredging a load on the Essayons.

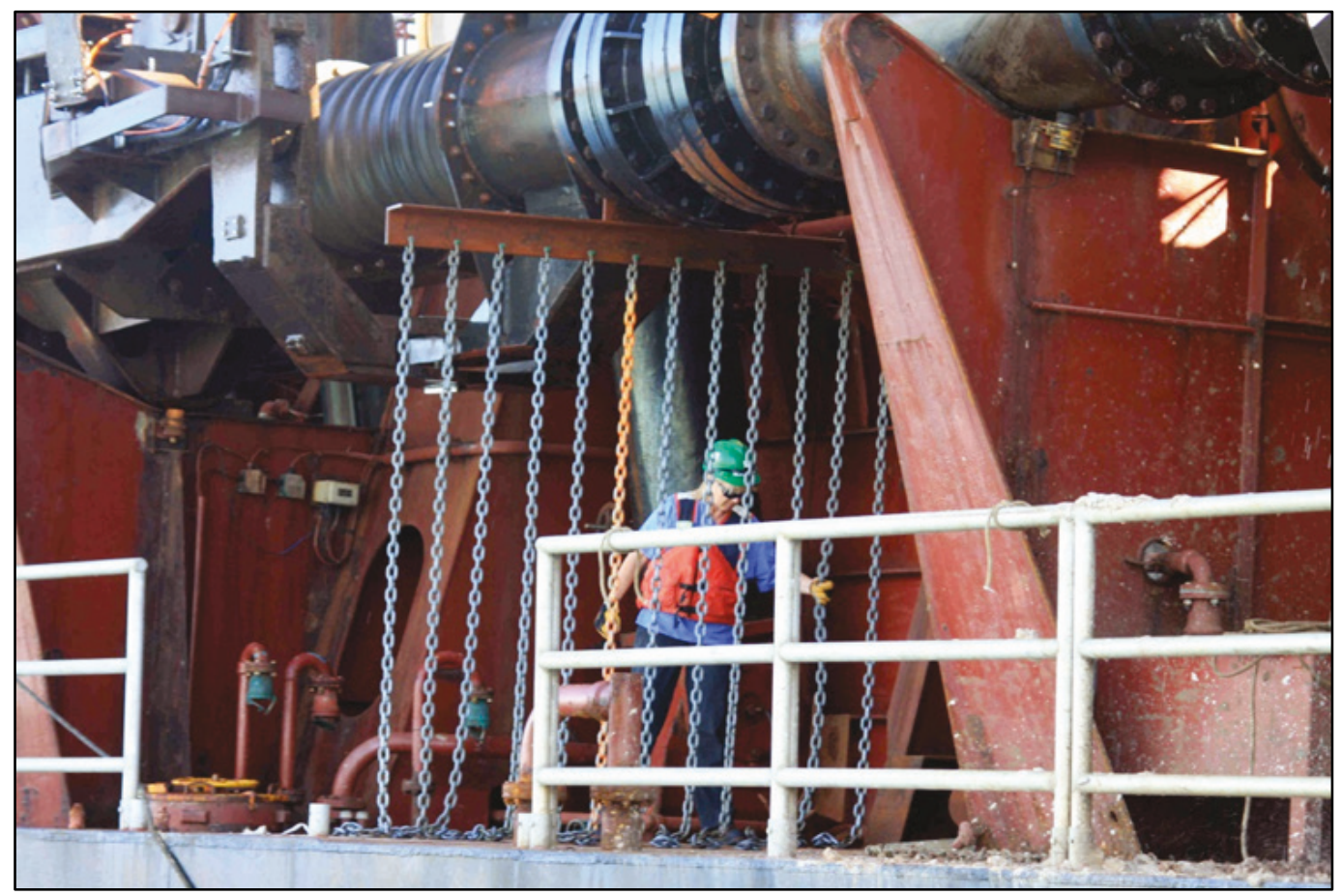




\section{Conclusions}

This study successfully demonstrated the feasibility for deploying turtle tickler chains (TTC) from the dragarm and the feasibility for mounting cameras on the dragarm and near the draghead for underwater monitoring. The successful demonstration proved that an acoustic camera could be used to monitor equipment performance in turbid water with extremely limited visibility and on a dynamic dragarm. The performance of the TTC could be clearly viewed with the acoustic camera, which showed that the chains maintained relatively even spacing, maintained contact with the bottom when the draghead was in the sediment, and did not entangle or become bunched together. The acoustic camera was also able to confirm that the draghead deflector was deployed correctly and generated the needed sediment wave to move turtles away from the draghead.

Rock and other features on the seafloor could be identified with the acoustic camera even in the turbid water whereas the high-definition and GoPro cameras could provide only very limited images of these features during very brief periods of clear water. Although no sea turtles were seen with the acoustic camera during this study, it is believed that a sea turtle could be identified with the acoustic camera system as was deployed on the dragarm.

This study demonstrated for the first time that acoustic cameras could be used to provide underwater monitoring of dredge equipment such as TTC, draghead deflectors, and dragheads, as well as potentially monitor some forms of sea life near the draghead during active dredging operations. Additional studies would need to be conducted to determine the level of accuracy and detail with which species identifications could be made using it. Due to the extreme vulnerability of any cameras attached on the dragarm, substantial effort should be made to design robust mounts and protective housings for underwater cameras in future studies of this type.

Recommendations for future evaluations similar to this study include the following:

- relocate the acoustic camera to a position forward of the TTC to minimize risk from damage when the draghead buries into the sediment 
- provide a protective housing around the camera to prevent debris from snagging the camera and to minimize damage from impacts into the sediment

- provide a robust lanyard system for the acoustic camera housing such as a metal cord with solid mounted fastening points as a safety line in case the camera system is knocked off the dragarm during dredging

- conduct evaluations in a location with a harder sediment bottom (e.g., sand) to provide a more consistent dredging environment with safer conditions for the camera equipment

- conduct evaluations with the visual cameras in a less turbid environment such as an open borrow area or a channel with strong currents that would clear the turbidity away between tests

- reinforce or relocate the tickler chains to minimize damage to the hanger base during dredging.

This study was the first step in evaluating TTC as a potential replacement for draghead turtle deflectors. Given the physical construction and manner in which TTC are applied, they may be a more effective engineering control to reduce risk to turtles where sediment types and debris prevent the use, or reduce the efficacy, of deflectors. When dredging in soft unconsolidated bottoms, it is sometimes difficult to tell if the dragheads are on the sea floor because the bearing strength of the sediment cannot support the dragarms weight. Therefore, the dragheads could be suspended off the sea floor and potentially not create the required 15 to $20 \mathrm{~cm}$ ( 6 to $8 \mathrm{in}$.) of sediment penetration. The TTC may be significantly more efficient in this type of dredging situation.

Although this study demonstrated the feasibility for deploying TTC and increased understanding of the underwater performance of TTC during dredging, it did not address the effectiveness of TTC to reduce incidental take of turtles. That evaluation would require analysis of endangered species observer data from the project as well as other hopper dredging projects where TTC are similarly used. Optimally, this analysis should be done with observer data from dredging projects when TTC were deployed in lieu of the draghead turtle deflector. Subsequent successful TTC evaluations must be conducted to demonstrate their effectiveness to reduce incidental turtle takes before it is possible to replace the draghead turtle deflector as the primary engineering design for protecting turtles during U.S. hopper dredging projects. 


\section{References}

Dickerson, D., M. Wolters, C. Theriot, and C. Slay. 2004. "Dredging Impacts on Sea Turtles in the Southeastern USA: A Historical Review of Protection.” In Proceedings of the $17^{\text {th }}$ World Dredging Congress, Vol. 27, Hamburg, Germany.

National Marine Fisheries Service. 2016. Endangered Species Act - Section 7 Consultation Biological Opinion and Conference Opinion, National Marine Fisheries Service-Pacific Islands Region-Protected Resources Division. NMFS File No. PIR-2014-9570, PIRO Reference No. I-PI-15-1218-AG, 3 Mar 2016.

Urick, R. J. 1983. Principles of Underwater Sound, ( $3^{\text {rd }}$ ed.). New York: McGraw-Hill.

USACE Operations and Dredging Endangered Species System (ODESS). 2017. Accessed 30 November. http://dqm.usace.army.mil/ODESS/\#/.

USACE Sea Turtle Protection and Data Warehouse. 2018. Accessed 9 February. https://el.erdc.dren.mil/projfact.cfm?ld=29\&Code=Programs.

U.S. Army Engineer Waterways Experiment Station. 1997. Sea Turtle Research Program Summary Report. Technical Report CHL-97-31. Vicksburg, MS: U.S. Army Engineer Waterways Experiment Station.

Van Veen, B. D., and K. M. Buckley. 1988. "Beamforming: A Versatile Approach to Spatial Filtering.” IEEE Asp Magazine 5(2): 4-24. 


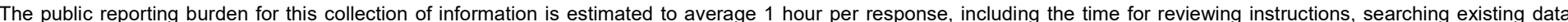

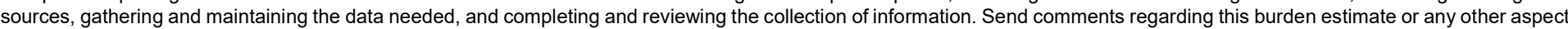

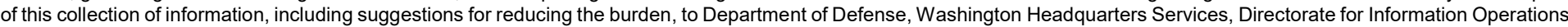

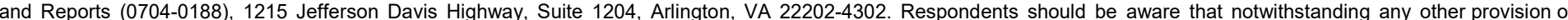
law, no person shall be subject to any penalty for failing to comply with a collection of information if it does not display a currently valid OMB control number.

PLEASE DO NOT RETURN YOUR FORM TO THE ABOVE ADDRESS.

\begin{tabular}{l|l|l}
$\begin{array}{l}\text { 1. REPORT DATE } \\
\text { May } 2018\end{array}$ & $\begin{array}{l}\text { 2. REPORT TYPE } \\
\text { Final Report }\end{array}$ & 3. DATES COVERED (From - To)
\end{tabular}

\section{TITLE AND SUBTITLE}

Use of an Acoustic Camera to Evaluate the Performance of Tickler Chains and Draghead Deflectors for Sea Turtle Protection during Hopper Dredging in the United States of America 5a. CONTRACT NUMBER

5b. GRANT NUMBER

5c. PROGRAM ELEMENT NUMBER

5d. PROJECT NUMBER

468436

5e. TASK NUMBER

5f. WORK UNIT NUMBER

8. PERFORMING ORGANIZATION REPORT NUMBER

ERDC TR-18-4

\section{SPONSOR/MONITOR'S ACRONYM(S)} USACE

U.S. Army Corps of Engineers

Washington, DC 20314-1000

\section{SPONSOR/MONITOR'S REPORT} NUMBER(S)

\section{DISTRIBUTION/AVAILABILITY STATEMENT}

Approved for public release; distribution is unlimited.

\section{SUPPLEMENTARY NOTES}

\section{ABSTRACT}

Potential risk for incidental take of sea turtles exists during hopper dredging throughout sea turtle coastal habitats. While the international dredging community has incorporated turtle protection methods developed by the U.S. Army Corps of Engineers, alternative protection measures have also been tried. One such method is a curtain of chains hanging off the dragarm pipe ahead of the draghead, which is intended to disturb a turtle on or near the seafloor and avoid a turtle take by the draghead. Although these turtle tickler chains (TTC) have been used overseas, neither operational performance nor effectiveness in protecting sea turtles has been documented.

This study was the first step in evaluating TTC as a potential replacement for draghead turtle deflectors. The primary objective was to evaluate and document operational performance of this technology, not effectiveness of reducing incidental take. TTC operational performance was monitored using underwater camera systems over a short period of time whereas effectiveness for reducing incidental take of sea turtles would require analysis of endangered species observer monitoring data collected over a longer period. This study successfully demonstrated operational feasibility of deploying TTC off the dragarm and feasibility for mounting acoustic cameras on the dragarm for underwater monitoring.

\section{SUBJECT TERMS}

Dredges, Dredging, Environmental protection, Sea turtles-Effect of dredging on

\begin{tabular}{|l|l|l|l|}
\hline 16. SECURITY CLASSIFICATION OF: & 17. LIMITATION OF \\
aBSTRACT \\
a. REPORT & b. ABSTRACT & c. THIS PAGE & \\
Unclassified & Unclassified & Unclassified & SAR \\
\hline
\end{tabular}

\begin{tabular}{l|l}
$\begin{array}{l}\text { 18. NUMBER OF } \begin{array}{l}\text { NaGeS } \\
\text { PAGES }\end{array} \\
39\end{array}$ & $\begin{array}{l}\text { 19ame OF RESPONSIBLE PERSON } \\
\text { Timothy Welp }\end{array}$ \\
\cline { 2 - 3 } & $\begin{array}{l}\text { 19b. TELEPHONE NUMBER (Include area code) } \\
601-634-2083\end{array}$
\end{tabular}




\section{PERFORMING ORGANIZATION NAME(S) AND ADDRESS(ES) (continued)}

Environmental Laboratory

U.S. Army Engineer Research and Development Center 3909 Halls Ferry Road

Vicksburg, MS 39180-6199

Coastal and Hydraulics Laboratory

U.S. Army Engineer Research and Development Center 3909 Halls Ferry Road

Vicksburg, MS 39180-6199

U.S. Army Engineer District, San Francisco 1455 Market St \#16

San Francisco, CA 94103

Great Lakes Dredge and Dock 2122 York Road

Oak Brook, IL 60523 